\title{
Using Scintillometry to Estimate Sensible Heat Fluxes over Water: First Insights
}

\author{
M. N. Bouin ${ }^{a, *}$, D. Legain ${ }^{b}$, O. Traullé ${ }^{b}$, S. Belamari ${ }^{b}$, G. Caniaux ${ }^{b}$, A. Fiandrino $^{c}$, F. Lagarde $^{c}$, \\ J. Barrié ${ }^{b}$, E. Moulin ${ }^{b}$ and G. Bouhours ${ }^{b}$
}

\begin{abstract}
${ }^{a}$ Centre de Météo Marine, CNRM, Météo France, 13 rue du Chatellier, CS12804, 29228 Brest Cedex 2, France
${ }^{\mathrm{b}}$ CNRM-GAME, URA 1357, Météo France CNRS, 42 Avenue Coriolis, 31057 Toulouse Cedex, France

${ }^{c}$ Laboratoire Environnement Ressources Languedoc Roussillon, Ifremer, Bd Jean Monnet, BP 171, 34203 Sète Cedex, France
\end{abstract}

*: Corresponding author : Marie-Noëlle Bouin, email address : marie-noelle.bouin@meteo.fr

\begin{abstract}
:
An extra large aperture scintillometer (XLAS) was used over several months across the Thau Lagoon (South of France) to retrieve one-wavelength scintillation and, thence, sensible heat flux. We present the experiment with the XLAS, an eddy-covariance station and meteorological stations measuring on or near the Thau Lagoon. Changes implemented to adapt the scintillometry processing schemes to the above water conditions are presented together with a full error budget, including sensitivity tests to the relevant parameters of the scintillometer processing scheme. The XLAS error budget amounts to $16 \%$ (systematic part) $\pm 50 \%$ (random part). Sensible heat fluxes obtained using the XLAS under unstable atmospheric conditions are then compared to eddy-covariance estimates used as a reference. The scintillometry technique proved to perform satisfactorily in such a watery environment. Some discrepancies observed between the XLAS and eddy-covariance measurements were investigated according to the lagoon fraction of the source area, to discriminate whether they were related to deviations from the Monin-Obukhov similarity theory or to different atmospheric conditions at the respective instrument locations. Local atmospheric conditions agreed well with theMonin-Obukhov similarity theory, especially measurements with source areas largely composed of the lagoon surface. Retaining only the measurements with almost only the lagoon surface in the source area improved the agreement between the XLAS and eddy-covariance measurements. The remaining discrepancies are interpreted as being due to significant location differences between the two instruments, resulting in different atmospheric conditions, and to size differences in the source areas.
\end{abstract}

Keywords: Air-sea fluxes ; Eddy covariance ; Footprint ; Monin-Obukhov similarity theory ; Scintillometry ; Sensible heat flux 


\section{Introduction}

2 Accurate estimates of turbulent fluxes at sea (or over water bodies) are crucial for

3 various applications in the atmospheric and oceanographic sciences, and in

4 weather forecasting. They are required, for instance, to improve mesoscale

5 atmospheric circulation models, to better constrain the upper level ocean heat

6 budget, and to improve knowledge and so flux parametrization in Numerical

7 Weather Prediction models. Their precise measurements usually rely on short-

8 term, difficult-to-set-up, labour-intensive, very costly sea campaigns. The most

9 reliable technique to retrieve turbulent fluxes over water, in particular at sea, is so

10 far considered to be eddy covariance (EC). Wind, temperature and humidity

11 fluctuations are measured using high frequency, fast response sensors on a fixed

12 or moving platform (e.g. on a shipborne mast during scientific cruises, as in Weill

13 et al. (2003)). The momentum, and sensible and latent heat fluxes are then

14 retrieved using the full spectrum (eddy covariance method) or the inertial part

15 only (inertial dissipation method). The EC method has proved to be the most

16 accurate method independently of the atmospheric or surface (roughness)

17 conditions but it is complicated to set up properly and flow distortion corrections

18 need to be applied (Yelland et al. 1998; Bourras et al. 2009).

19 We present, here, the potential contribution of scintillometry as a new measuring

20 technique for assessing turbulent heat fluxes at sea.

21 Scintillometry has been used increasingly over the recent decades to retrieve

22 sensible heat fluxes (one-wavelength system) or both sensible and latent heat

23 fluxes (dual-wavelength system). It was first shown to perform reliably in

24 comparison with eddy covariance measurements over homogeneous terrain

25 (Andreas 1988a; De Bruin et al. 1995; Lagouarde et al. 2006; Zeweldi et al.

26 2010). More recently, it has also been validated against eddy covariance over

27 heterogeneous landscapes (Meijninger et al. 2002; Beyrich et al. 2002; Ezzahar et

28 al. 2009). It has proved to be especially useful for deriving aggregated fluxes over

29 heterogeneous parcels where EC estimates only give access to local information

30 (Ezzahar and Chehbouni 2009). Large Aperture Scintillometers (LAS) in

31 particular are less prone than others to saturation, which occurs under highly

32 turbulent conditions. They can operate over path lengths of several kilometres and

33 provide sensible heat fluxes aggregated over large areas comparable to one or 
1 several pixels of a satellite image or numerical weather model output. A review of

2 the capabilities and recent uses of scintillometry can be found in Moene et al.

3 (2009).

4 In this study, we use data collected during the 2009 Thau Lagoon Experiment to

5 investigate whether the LAS technique can be used reliably over lakes or sea to

6 retrieve sensible heat flux $(H)$ values. The scintillometry technique has, to our

7 knowledge, been used only once to estimate sensible heat fluxes over sea or lakes

8 (McJannet et al. 2011). This paper presents the results of one of the first attempts

9 to extend its domain of use and compares scintillometry sensible heat flux

10 estimates with those obtained by eddy covariance.

11 The paper is organized as follows. In the next part, we present the EC analysis and

12 quality check, the scintillometer processing scheme and its adaptation to the air-

13 sea flux assessment. Part 3 presents the Thau Lagoon (South of France)

14 experiment and the instruments. The results of some sensitivity tests used to

15 derive an error budget are presented in part 4. Part 5 validates the sensible heat

16 fluxes by comparing them to the eddy covariance fluxes. Using a detailed

17 footprint and wind sector analysis, restrictions are identified on the use of

18 scintillometry in such an environment.

\section{Theory}

20 In this section, the adaptation of the Large Aperture Scintillometry processing

21 scheme to air-sea flux estimation is described. For each step of the processing, the

22 changes made in connection with the experimental conditions are reported, some

23 of them in connection with the results of the sensitivity tests (part 4). The

24 instrument used in this study was an Extra Large Aperture Scintillometer (XLAS)

25 manufactured by Kipp \& Zonen (K\&Z). Some of the steps described below are

26 specific to this instrument but all the adaptations reported may be generalized to

27 any scintillometry measurements performed over water. When necessary,

28 additional input parameters were provided by in situ measurements at the

29 Marseillan station (see Section 3, Table 1, and Fig. 4 and 5 for a full description

30 of the experiment). 


\section{$1 \quad$ 2.1 From Raw Measurements to $C_{n}^{2}$}

\section{$2 \quad$ 2.1.1 Measurement Errors}

3 Electromagnetic radiation emitted by the XLAS transmitter is scattered by the

4 atmospheric turbulence, and the resulting variations in the signal intensity are

5 recorded by the receiver. These signal intensity fluctuations (scintillation) can

6 then be related to the structure parameter of the refractive index of the air $C_{n}^{2}$

7 averaged over the path. (In the following, the $C_{n}^{2}$ notation refers to this path-

8 averaged value.) In their LAS scintillometer intercomparison study, Kleissl et al.

9 (2008; 2009) pointed out some discrepancies (up to 20\%) among measurements

10 performed using several K\&Z LAS instruments as well as among measurements

11 performed using $K \& Z$ instruments and scintillometers from other manufacturers

12 (e.g. Scintec). These inaccuracies, which are attributed to electronic or optical

13 problems in the K\&Z LAS, directly affect the measurement of the structure

14 parameter of the air refractive index, $C_{n}^{2}$. In a recent study, Van Kesteren and

15 Hartogensis (2011) observed two systematic errors affecting the $C_{n}^{2}$ measurements

16 from K\&Z LAS. The first one (called high $C_{n}^{2}$ error) may have been due to a poor

17 focal alignment of the receiver detector and the transmitter diode.

18 The second one (called low $C_{n}^{2}$ error) corresponded to the bias detected by Kleissl

19 et al. (2009) and affects $U_{C_{n}{ }^{2}}$ (output signal of the XLAS), from which $C_{n}^{2}$ itself is

20 usually calculated. Two different relations may be used to derive $C_{n}^{2}$ from the

21 various outputs of the LAS (or XLAS). A first assessment of the presence of this

22 low $C_{n}^{2}$ error in the XLAS signal may thus be obtained by comparing these two

23 relations.

24 The first one is based on the demodulated signal ( $I$, corresponding to the signal

25 strength or intensity averaged over the optical path) and relates the air refractive

26 index $C_{n}^{2}$ to the mean variance of the logarithmic intensity $\sigma_{\ln (I)}^{2}$ (Wang et al., 27 1978):

$$
C_{n}^{2}=1.12 \sigma_{\ln (I)}^{2} D^{7 / 3} L^{-3}
$$

29 where $D$ is the aperture diameter and $L$ the path length, and:

$$
\sigma_{\ln (I)}^{2}=\ln \left(1+\frac{\sigma_{I}^{2}}{\overline{I^{2}}}\right)
$$


1 where $\sigma_{I}^{2}$ is the signal intensity variance.

2 The second relation is specific to the K\&Z XLAS instrument and uses the high

3 frequency raw output signal multiplied by $10^{15}$ (whose mean value is hereafter

4 referred to as $P U_{C_{n}^{2}}$ ), namely ( Kipp \& Zonen 2007):

$$
C_{n}^{2}=P U_{C_{n}^{2}} 10^{-15}
$$

6 We checked the correspondence between the values of $C_{n}^{2}$ obtained using Eq. 1

7 and Eq. 3, using a log-log comparison. The agreement was excellent, with

8 correlation coefficients over 0.99 and an RMS (relative value) of $6 \%$. We thus

9 conclude that the K\&Z XLAS is probably not subject to this low $C_{n}^{2}$ systematic

10 error. Equation 1 is used in the following because it is more direct and thus 11 inherently safer.

\section{$12 \quad 2.1 .2$ Saturation}

13 One advantage of the XLAS over the laser $(\mathrm{mm})$ scintillometer is that it is less

14 subject to saturation. Saturation occurs in strong scintillation: as the variance of 15 the logarithmic intensity $\sigma_{\ln (I)}^{2}$ becomes saturated, the relation between $C_{n}^{2}$ and 16 this variance (Eq. 1) is no longer valid. Saturation of LAS measurements has been 17 intensively studied (e.g. Wang et al. 1978; Hill and Clifford 1981; Ochs and Hill 18 1982; Frehlich and Ochs 1990). For a review of saturation effects on the XLAS, 19 see Kohsiek et al. (2006). With the parameters corresponding to the scintillometer 20 used in this experiment, the most restrictive criterion for non-saturation 21 corresponds to the results of Frehlich and Ochs (1990) with:

$$
C_{n}^{2}<0.057 D^{5 / 3} L^{-8 / 3} \lambda^{1 / 3}
$$

23 where $\lambda$ is the scintillometer optical wavelength. Removing data according to this

24 criterion led to rejection of $\approx 1 \%$ of the raw data.

\section{$25 \quad 2.2$ From $C_{n}^{2}$ to $C_{T}^{2}$}

\section{2.2.1 T-q Correlation}

27 The relationship between the structure parameter of the air refractive index $C_{n}^{2}$ and 28 the structure parameters of the pressure $P$, air temperature $T$ and specific humidity 
$1 q$ has been extensively described (e.g. Moene 2003; Moene et al. 2004). Below is

2 a brief summary to present the changes made in the XLAS processing scheme.

3 Except for rare cases where the temperature and humidity fluctuations are very

4 low, the effects of the pressure fluctuations may be safely neglected, and the

5 relationship between $C_{n}^{2}$ and $C_{T}^{2}$ depends on $T$ and $q$ only (Wesely 1976):

$$
C_{n}^{2} \approx \frac{A_{T}^{2}}{T^{2}} C_{T}^{2}\left(1+2 \frac{A_{q}}{q} \frac{T}{A_{T}} R_{T q} \frac{c_{p}}{L_{v}} \beta^{-1}+\frac{A_{q}^{2}}{q^{2}} \frac{T^{2}}{A_{T}^{2}}\left(\frac{c_{p}}{L_{v}}\right)^{2} \beta^{-2}\right)
$$

7 where $A_{T}$ and $A_{q}$ are coefficients related to the temperature and humidity

8 fluctuations for the XLAS wavelength, $R_{T q}$ is the correlation coefficient between

9 the temperature and humidity fluctuations, $c_{p}$ is the specific heat capacity of air at

10 constant pressure, $L_{v}$ the specific latent heat of vaporization, and $\beta$ the Bowen

11 ratio. In Eq. 5 and the following, $T$ and $q$ refer to the mean values of temperature

12 and specific humidity over the measurement averaging interval. When using

13 scintillometry to derive heat fluxes over land surfaces, it is usually assumed that

$14 R_{T q}$ is equal to $+/-1$, depending on the sign of $\beta$ (e.g. Ludi et al. 2005). For typical

15 atmospheric conditions, this leads to:

$$
C_{T}^{2} \approx\left(\frac{T^{2}}{0.7810^{-6}}\right)^{2} C_{n}^{2}\left(1+\frac{0.03}{\beta}\right)^{-2}
$$

17 In the case of the Thau Lagoon experiment, the correlation coefficient $R_{T q}$ was

18 closer to zero. An analysis of the EC measurements showed that its mean absolute

19 value was $0.046 \pm 0.066$. We then followed Odhiambo et al. (2009) in using a

20 mean value of this correlation coefficient close to zero in Eq. 5. A new

21 relationship between $C_{n}^{2}$ and $C_{T}^{2}$ is then:

$$
C_{T}^{2} \approx\left(\frac{T^{2}}{0.7810^{-6}}\right)^{2} C_{n}^{2}\left(1+\left(\frac{0.03}{\beta}\right)^{2}\right)^{-1}
$$

23 This equation 7 is used in the following.

\section{$24 \quad$ 2.2.2 Bowen Ratio}

25 In contrast with land surface measurements, Bowen ratios over water are usually 26 very low (less than 0.5). The value of this Bowen ratio $\beta$ in Eq. 7 should be known 27 as precisely as possible. The best option here would probably be to use the Bowen 
1 ratio derived from the EC measurements, but one of the aims of this study was to

2 assess the quality of the XLAS sensible heat fluxes over water using the EC

3 measurements as a reference. It was thus desirable to obtain results as independent

4 as possible of the EC technique. Bowen ratio values were obtained using the

5 gradient method together with atmospheric parameters from the Marseillan

6 station:

$$
\beta=\frac{c_{p}}{L_{v}} \frac{T_{s}-T}{e_{s}-e}
$$

$8 T_{s}$ being the water surface temperature, $e_{s}$ the saturation vapour pressure and $e$ the

9 partial pressure of water vapour. Figure 1 presents a comparison (histograms) of

10 the gradient and EC-derived Bowen ratios over the experimental period. The

11 mean difference (EC-derived minus gradient) is $0.174 \pm 1.218$, and the correlation

12 coefficient is 0.70 . While the agreement is good for low Bowen ratio values (less

13 than 0.25), the gradient method fails to reproduce Bowen ratios between 0.5 and

141.2 as derived from eddy covariance measurements.

15 In the following, Bowen ratios computed using the gradient method on the

16 Marseillan measurements are used.

\section{$17 \quad 2.3$ From $C_{T}^{2}$ to Sensible Heat Flux}

\section{$18 \quad$ 2.3.1 Effect of Humidity}

19 To obtain sensible heat flux from the temperature structure parameter, it is 20 necessary to use the surface layer similarity relationship for $C_{T}^{2}$, which is part of

21 Monin-Obukhov Similarity Theory (MOST).

$$
\frac{C_{T}^{2} z^{2 / 3}}{T_{*}^{2}}=\varphi_{T}\left(\frac{z}{L_{M O}}\right)
$$

23 where $z$ is the measurement height, $T_{*}$ the scale parameter for temperature, $L_{M O}$

24 the Obukhov length, and $\varphi_{T}$ a universal function of $z / L_{M O}$, and the additional 25 relationships for $L_{M O}$ and $T_{*}$ :

$$
T_{*}=\frac{H}{u_{*} \rho c_{p}}
$$

$$
L_{M O}=\frac{u_{*}{ }^{2} T_{v}}{g T_{v^{*}} k}
$$


1 with $u_{*}$ the friction velocity, $\rho$ the air density, $T_{v}$ the virtual temperature of air, $g$

2 the gravitational attraction mean value, $T_{v^{*}}$ the scale parameter for temperature

3 including the buoyancy flux, and $k$ the von Karman constant (taken equal to 0.4).

4 The virtual temperature and scale parameter for temperature including humidity

5 may be expressed as:

$$
\begin{aligned}
T_{v} & =T(1+0.61 q) \\
T_{v^{*}} & =T_{*}\left(1+0.61 T_{v} \frac{c_{p}}{L_{v}} \beta^{-1}\right)
\end{aligned}
$$

8 These expressions for $T_{v}$ and $T_{v^{*}}$ are used in Eq. 11 to express $L_{M O}$ as a function of

$9 u * T$, and $T_{*}$ only. The Bowen ratio used in Eq. 13 was deduced from the

10 Marseillan atmospheric parameters using the gradient method as in section 2.2.4.

\section{$11 \quad$ 2.3.2 Stratification}

12 Stratification (unstable or stable) specification within the scintillometry 13 processing must be established from independent information, for instance 14 atmospheric/hydrological measurements. As this study was a first approach to 15 evaluate whether scintillometry was capable of retrieving sensible heat fluxes over 16 water, we restricted ourselves to data corresponding to unstable cases.

17 There are several possible criteria for selecting unstable stratification situations.

18 All of them used measurements made at the Marseillan station (Figure 2 and 3), 19 which is not exactly collocated with the XLAS path. An assumption of the 20 unstable data selection was that the stratification was the same in Marseillan and 21 along the scintillometer path.

22 Unstable stratification may be defined using the virtual temperature difference 23 between the surface and the measurement height $\left(T_{v}{ }^{s}-T_{v}\right)$, the Obukhov length 24 computed using a bulk algorithm (see section 3.5) $\left(L_{M O}^{b u l k}\right)$, or the Obukhov length 25 obtained using the eddy covariance method $\left(L_{M O}^{E C}\right)$. The first two criteria $\left(T_{v}{ }^{s}-T_{v}\right.$ $26>0.5{ }^{\circ} \mathrm{C}$ and $\left.z / L_{M O}^{\text {bulk }}<-0.05\right)$ were used together to select data corresponding to 27 unstable stratification. To ensure the consistency of the XLAS processing with the 28 eddy covariance measurements, the data were filtered according to the EC-derived 29 Obukhov length criterion $\left(z / L_{M O}^{E C}<-0.05\right)$; this led to the rejection of a further $4 \%$ 30 of the data. Finally, only unstable atmospheric situations (independently of night31 or day-time period) are retained in the following. This represents more than $80 \%$ 32 of the entire Thau Lagoon dataset. 


\section{$1 \quad$ 2.3.3 Roughness Length}

2 Equations 9 and 11 were combined in an iterative way to solve for $T_{*}, u_{*}$ and $L_{M O}$.

3 As an additional assumption was needed to determine these 3 parameters from 2

4 equations, $u_{*}$ was estimated from the roughness length $\mathrm{z}_{0}$ and the wind speed

5 using the following relationship:

$$
u_{*}=\frac{k U_{10}}{\ln \left(z / z_{0}\right)-\Psi_{m}\left(z / L_{M O}\right)+\Psi_{m}\left(z_{0} / L_{M O}\right)}
$$

7 where $\Psi_{m}$ is the universal similarity function for momentum, and $U_{10}$ the mean

8 horizontal wind velocity at $10 \mathrm{~m}$. As a first guess, a simplified relationship was

9 used for $u_{*}$ with a roughness length $z_{0}=10^{-4} \mathrm{~m}$ :

$$
u_{*}=\frac{k U_{10}}{\ln \left(z / z_{0}\right)}
$$

11 Unlike the case for land surfaces, this roughness length may change very quickly

12 over a lake or sea as it depends on the sea state and thus on the wind. The

13 scintillometry solving algorithm was adapted to adjust this $z_{0}$ iteratively using the

14 relationship of Smith (1988):

$$
z_{0}=0.011 \frac{u_{*}^{2}}{g}+0.11 \frac{v}{u_{*}}
$$

16 where $v$ is the kinematic viscosity of water.

\section{$17 \quad$ 2.3.4 Similarity and Stability Functions}

18 Several universal functions $\varphi_{T}$ (Eq. 9) have been used by different authors (e.g.

19 Andreas 1988b; Hill et al. 1992; Thiermann and Grassl 1992; De Bruin et al.

20 1993; Edson and Fairall 1998). In the following, the function of Edson and Fairall

21 (1998) was used, viz.:

$$
\varphi_{T}\left(\frac{z}{L_{M O}}\right)=c_{\mathrm{T}_{1}}\left(1-c_{\mathrm{T}_{2}} \frac{z}{L_{M O}}\right)^{-2 / 3}
$$

23 with $C_{\mathrm{T}_{1}}=5.92$ and $C_{\mathrm{T}_{2}}=8$.

24 The universal stability function for momentum under unstable conditions $\Psi_{m}$ (Eq.

25 14) was defined using the Businger-Dyer expression (Paulson 1970): 


$$
\Psi_{m}\left(\frac{z}{L_{M O}}\right)=2 \ln \left(\frac{1+x}{2}\right)+\ln \left(\frac{1+x^{2}}{2}\right)-2 \arctan (x)+\frac{\pi}{2}
$$

2 with:

$$
x=\left(1-16 \frac{z}{L_{M O}}\right)^{1 / 4}
$$

\section{$4 \quad 3$ Field experiment}

\section{$5 \quad 3.1$ The Thau Lagoon}

6 The Thau Lagoon lies between $43^{\circ} 20^{\prime} \mathrm{N}$ and $43^{\circ} 28^{\prime} \mathrm{N}$, and between $3^{\circ} 32^{\prime} \mathrm{E}$ and

$7 \quad 3^{\circ} 42^{\prime} \mathrm{E}$, along the French north-west Mediterranean coast. Its maximum length

8 (north-east - south-west) is about $19 \mathrm{~km}$, its width is less than $4.5 \mathrm{~km}$ and its

9 mean depth is $4 \mathrm{~m}$ (see Fig. 3 for bathymetry information). The lagoon deepens to

$1010 \mathrm{~m}$ in the north-east and a maximum of $32 \mathrm{~m}$ is reached at the Fosse de la Vise

11 (north-east). The salinity is generally slightly less than in the nearby sea and

12 varies seasonally between 31 and 39 depending on the evaporation and

13 precipitation rates, and on sea salinity variations (due to the nearby river runoff

14 for instance).

15 The lagoon is connected to the sea through several passes or channels (in Sète, see

16 Figure 2). Most of the water exchanges with the sea are due to tidal currents, with

17 average daily values between $0.7 \times 10^{6}$ and $3.8 \times 10^{6} \mathrm{~m}^{3}$. Sea tides have a weak

18 influence on the lagoon water level (less than $100 \mathrm{~mm}$ between peak and

19 minimum). The surface current on the Thau Lagoon itself is considered as very

20 weak, and can be safely neglected in the following.

\section{$21 \quad 3.2$ Scintillometry}

\section{$22 \quad 3.2 .1$ Instruments}

23 We used an Extra Large Aperture Scintillometer manufactured by Kipp \& Zonen

24 with technical characteristics close to those described by Kohsiek et al. (2002):

25 the signal wavelength is $880 \mathrm{~nm}$, the effective aperture $0.32 \mathrm{~m}$ and the focal

26 length $0.61 \mathrm{~m}$. Such instruments can operate over path lengths ranging between

271000 and $8000 \mathrm{~m}$, with a minimum height above ground of $3 \mathrm{~m}$. The XLAS was

28 set up over a path of $4850 \mathrm{~m}$ between Loupian Saint-Félix near the small town of 
1 Mèze and the IUT de Chimie in Sète (on the narrow tongue or 'lido' located

2 between the Thau Lagoon and the sea - Figure 2). Measurements of the signal

3 intensity were performed every second, then averaged over 10-min periods. The

4 instrument operated continuously for nearly 8 months, from 15 January to 9

5 September 2009. Except for very basic maintenance (checking the transmitter-

6 receiver alignment and cleaning the windows of the transmitter and receiver every

7 month) it worked reliably unattended. The data were automatically downloaded,

8 stored in situ, and transmitted in real time during the whole experiment.

\section{$9 \quad$ 3.2.2 Scintillometer Effective Height}

10 The transmitter height above water was $14 \mathrm{~m}$ and the receiver height $12 \mathrm{~m}$. As the

11 optical path lay entirely over water (Fig. 2 and 3a), the beam height variation was

12 small and almost entirely due to this height difference, resulting in an effective

13 height of $13 \mathrm{~m}$. As already pointed out by several studies, scintillometry results

14 are especially sensitive to the effective height (e.g. Hartogensis et al. 2003). A

15 correction was made for the Earth's curvature effect on the 4850-m-long path

16 (reaching $0.4 \mathrm{~m}$ ). The final effective height $z$ used in the data analysis was thus

$17 \quad 12.6 \mathrm{~m}$. Note that, in contrast most studies using scintillometry over cultivated

18 areas, forest patches or cities, the displacement height $z_{d}$ which is directly related

19 to the roughness length, was negligible over water. The classical $z-z_{d}$ height

20 difference used in scintillometry processing reduces to the effective height $z$ here.

\section{$21 \quad 3.3$ Eddy Covariance Measurements}

22 Eddy covariance measurements were performed continuously from May to 23 November 2009 at the Marseillan site (see Fig. 2 and 3b, and Table 1 for the 24 complete list of instruments). The experimental platform where the high 25 frequency instruments were set up is deeply anchored (metal poles several metres 26 long) in the lagoon bottom and may be considered stable at the measurement 27 frequency. The water depth at the platform position is $4.2 \pm 0.3 \mathrm{~m}$.

\section{$28 \quad$ 3.3.1 Data Processing}

29 The eddy covariance raw data were processed using the turbulence software 30 package TK2 (Mauder and Foken 2004), which has been compared with several 31 other turbulent flux packages (Mauder et al. 2008) and was shown to perform 
1 accurately. Several corrections were applied during the processing, in an iterative

2 way because of their interdependence (Mauder and Foken 2006). They concerned

3 the conversion of fluctuations of the sonic temperature into fluctuations of

4 temperature according to Schotanus et al. (1983), the correction for density

5 fluctuations (temperature and humidity term, depending on the sensors used)

6 according to Webb et al. (1980), and the correction of spectral loss according to

7 Moore (1986), using the spectra models of Højstrup (1981) and Kaimal et al.

8 (1972) for unstable conditions. The time delay of the gas analyzer with respect to

9 the sonic anemometer was determined by calculating and maximizing cross

10 correlations. The cross-wind correction of the sonic temperature (Liu et al. 2001)

11 was not applied because it was already accounted for in the anemometer software.

12 The wind sensor orientation was corrected using the planar fit method on a period

13 of 10 days excluding observations with wind speed above $10 \mathrm{~m} \mathrm{~s}^{-1}$ (Wilczak et al.

14 2001).

\section{$15 \quad$ 3.3.2 Quality Control}

16 Several quality tests are implemented in the TK2 software. The steady state test

17 (Foken and Wichura 1996) compares the statistical parameters determined for the

18 averaging period of 30 minutes and for 6 intervals of 5 minutes within these 30

19 minutes. For the sensible heat flux determination, the average of the covariance of

20 the measured vertical wind $w$ and the sonic temperature $T_{s n}\left(\overline{w^{\prime} T_{s n}{ }^{\prime}}\right)$ determined

21 over the six 5-min interval is compared with the covariance of the same

22 parameters for the whole 30-min interval. The time series of the measurements is

23 considered to be steady state if the relative difference between the two

24 covariances is lower than $30 \%$. The Integral Turbulence Characteristics test (ITC;

25 Kaimal and Finnigan 1994) checks the development of turbulent conditions

26 through the similarity characteristics of the atmospheric turbulence. The modelled

27 and measured values of the standard deviation of a given parameter normalized by

28 the corresponding scale parameter are compared. For the sensible heat flux

29 determination, the ratio $\sigma_{T} / T_{*}$ modelled using the functions of Foken et al. (1991)

30 is compared to the measured values of $\sigma_{T} / T_{*}$, where $\sigma_{T}$ is the standard deviation

31 of the temperature. This ITC test is not applied under neutral conditions, when the

32 absolute value of the sensible heat flux is lower than $10 \mathrm{~W} \mathrm{~m}^{-2}$, because $\sigma_{T} / T_{*}$ is

33 not well defined in that case. 
1 We then used the overall flag system of Foken et al. (2004) as implemented in the

2 TK2 software. This scheme for sensible heat flux determination is based on the 3 results of the steady state test for $H$ and on the results of the ITC test for the $\sigma_{T} / T_{*}$

4 and the $\sigma_{w} / u_{*}$ time series, where $\sigma_{w}$ is the standard deviation of the vertical wind.

5 If the results of these two ITC tests disagree, the larger deviation is used for the

6 overall flag. As recommended by Mauder and Foken (2004), only the data with

7 overall flags of 1,2 , or 3 are kept for the analysis. The maximum deviations for

8 the two tests corresponding to the overall flags are given with the percentage of

9 our data for each flag in Table 2. More than $57 \%$ of the data are flagged 1 or 2 ,

10 corresponding to very good steady state conditions and good turbulence

11 conditions.

\subsection{Additional Measurements}

13 In addition to the EC station, three stations operated on and around the Thau

14 Lagoon during the experiment to measure atmospheric parameters: air

15 temperature, humidity, wind speed and direction were recorded at the Marseillan,

16 Crique, and Sète stations (Fig. 2), the latter also including pressure measurements.

17 This third station (Sète hereafter) was nearly collocated with the XLAS receiver

18 but, as it was located closer to the lagoon shore, the wind conditions were very

19 different from those observed at the Marseillan and Crique stations. The pressure

20 data measured in Sète are used in the following as representative of the other

21 locations.

22 Water surface temperature was recorded at the Marseillan and Crique stations,

23 using 0.2-m-deep shielded thermometers ( $T_{s}$ hereafter) and infra-red radiometers

24 ( $T_{s}^{I R}$ hereafter). The skin surface temperature provided by these infra-red

25 radiometers gave some hints on the surface temperature homogeneity over the

26 lagoon. Over the measurement time period, the mean difference between these

27 skin surface temperatures was $0.03 \pm 0.64{ }^{\circ} \mathrm{C}$, showing that, at the surface, the

28 lagoon evolves rather uniformly. The difference between water temperatures $\left(T_{s}\right.$ -

$\left.29 T_{s}^{I R}\right)$ in Marseillan (in Crique, respectively) reached $-1.3 \pm 0.75{ }^{\circ} \mathrm{C}\left(-3.8 \pm 1.1{ }^{\circ} \mathrm{C}\right.$,

30 resp.). Since $T_{s}^{I R}$ is more prone to calibration errors and biases (Kohsiek et al.

31 2007), $T_{s}$ is used as the surface temperature in the following.

32 Below, we consider data from 14 May to 7 September 2009 corresponding to the

33 common period between the XLAS, EC and other meteorological station 
1 measurements. The scintillometry measurements were averaged over 30-min

2 periods to be consistent with the other measurements.

\section{$3 \quad 3.4$ Mean Atmospheric Conditions}

4 Figure 4 gives a wind rose, a histogram of the wind speed, and a histogram of the

5 surface temperature difference at the Marseillan station for the data actually used

6 in this study.

7 The mean wind conditions were mostly moderate, with wind speeds up to $13 \mathrm{~m} \mathrm{~s}^{-}$

81 . The wind direction was mainly west-north-west to north-north-west, then east to

9 south, corresponding to wind blowing from inland (Tramontane) and from the sea

10 over the narrow strip of land respectively. Around $75 \%$ of the observations

11 corresponded to wind blowing along the XLAS path, in the 'continental' (north-

12 westerly wind) and 'lido' (south-easterly wind) sectors in Figure 4a. Wind

13 directions perpendicular to the XLAS path (wind blowing from the Thau Lagoon,

14 either from the south-west or from the north-east, 'lagoon' sector in Fig 6a) still

15 made up more than $25 \%$ of the data.

\section{$16 \quad 3.5$ Bulk Computation}

17 The principle of a bulk algorithm is to estimate the flux corresponding to the

18 variable $x$ (e.g. wind, heat or humidity) as $F_{x}=C_{x} U\left(\delta_{s}-\delta_{z}\right), C_{x}$ being a transfer

19 coefficient, and $\delta_{s}$ and $\delta_{z}$ the corresponding parameter measured at the surface

20 and at the height $z$. Using these relationships in combination with, for instance

$21 \tau=\rho u_{*}^{2}$ for the momentum flux $\tau$ or $H=\rho c_{p} u_{*} T_{*}$ (equivalent to Eq. 10) for the

22 sensible heat flux allows to write $u_{*}=C_{D}^{1 / 2} U$ and $u_{*} T_{*}=C_{H} U\left(T_{s}-T\right), C_{D}$ being

23 the transfer coefficient for the momentum flux and $C_{H}$ the transfer coefficient for

24 the sensible heat flux. These transfer coefficients can be evaluated from the 25 roughness length and the Obukhov length using the formulae:

$$
C_{D}=k^{2}\left(\ln \frac{z}{z_{0}}-\Psi_{m}\left(\frac{z}{L_{M O}}\right)\right)^{-2}
$$

27 and :

$$
C_{H}=k^{2}\left(\ln \frac{z}{z_{0}}-\Psi_{m}\left(\frac{z}{L_{M O}}\right)\right)^{-1}\left(\ln \frac{z}{z_{T}}-\Psi_{T}\left(\frac{z}{L_{M O}}\right)\right)^{-1}
$$

29 It is assumed here that the air temperature and the wind are measured at the same

30 height $z$. The roughness length and the Obukhov length are related to the friction 
1 velocity and to the scale parameter for temperature as shown by Eq. 16, and a

2 conjunction of Eq. 11 and 13. Similar relationships allow to express $z_{T}$ and the

3 universal function for temperature $\Psi_{T}$ from the same group of parameters. This

4 set of Eq. 11, 16, 20 and 21 together with the bulk relationships $u_{*}=C_{D}^{1 / 2} U$ and

$5 u_{*} T_{*}=C_{H} U\left(T_{s}-T\right)$ is used iteratively to solve for $u_{*}, T_{*}, z_{0}$ and $L_{M O}$, and thus to

6 obtain estimates of the momentum and sensible heat fluxes from measurements of

7 the mean wind, the air temperature and the surface water temperature.

8 In section 2.3.2 and here below, a bulk algorithm (COARE 3.0, Fairall et al.

9 2003) is used to estimate the Obukhov length, the roughness length or the sensible

10 heat flux.

\section{$11 \quad 3.6$ Data Representativeness}

12 For logistical reasons, the high-rate flux measurements and mean meteorological

13 parameters (Marseillan-EC station) were performed several kilometres south-

14 westward of the XLAS path (Fig. 2). In this part, we investigate whether the

15 measurements performed with XLAS are theoretically comparable to those

16 recorded at the (Marseillan-EC) reference station; namely, whether the respective

17 footprints cover each other or not.

18 A footprint analysis using the model of Schmid (1994) was performed for the 19 sensible heat flux along the scintillometer path, and for the temperature and wind 20 fields (Marseillan-EC station). Both footprints were computed using the FSAM 21 software (Schmid 1994), based on the analytical solution of the 2-D advection22 diffusion equation for non-neutral stratification.

23 The along-XLAS-path footprint integration was then computed by combining the

24 flux footprint itself with the weighting function of the XLAS as provided in the 25 XLAS manual (Meijninger et al. 2002; Kipp \& Zonen 2007). The Obukhov and 26 roughness lengths were computed using the bulk algorithm COARE 3.0 together

27 with atmospheric parameters observed at the Marseillan-EC station.

28 Typical footprints corresponding to wind blowing across (respectively along) the 29 XLAS path are shown Figure 5a (resp. 5b). These examples are based on 30 observed unstable stratification conditions corresponding to 15 July 2009 31 (respectively 15 May 2009), with an Obukhov length of $-8 \mathrm{~m}$ (-126 m), a 32 roughness length of $3.0 \times 10^{-5} \mathrm{~m}\left(1.8 \times 10^{-4} \mathrm{~m}\right)$, and a wind speed of $3.2 \mathrm{~m} \mathrm{~s}^{-1}$

$33\left(10.1 \mathrm{~m} \mathrm{~s}^{-1}\right)$. These situations are thus typical of very unstable, moderately windy 
1 lagoon conditions (slightly unstable, windy conditions resp.). Note that roughness

2 length was consistently an order of magnitude higher on 15 May 2009 compared

3 to the 15 July 2009 conditions.

4 These footprints correspond approximately to the maximum size of the XLAS

5 integrated source area observed during this experiment, and show clearly that 1)

6 the measurement footprints of the EC station and of the XLAS do not cover each

7 other, whatever the atmospheric conditions for unstable stratification; 2) the

8 respective sizes of these footprints or source areas are very different.

9 To further refine this, the same footprint analysis method was used to process the

10 source area accounting for $90 \%$ of the signal for every averaging interval of the

11 XLAS processing. The mean surface was $1.6 \times 10^{6} \mathrm{~m}^{2}$ (maximum value $4.4 \times 10^{6}$

$12 \mathrm{~m}^{2}$ ) for the XLAS, $2.3 \times 10^{3} \mathrm{~m}^{2}$ (maximum value $3.7 \times 10^{3} \mathrm{~m}^{2}$ ) for the EC station.

13 The actual fraction of lagoon (respectively land) surface was computed for each

14 XLAS measurement to check whether these XLAS measurements are

15 representative of the air-water interface or could have be influenced by land

16 surface conditions. The fraction of land surface in the XLAS footprints ranged

17 from 10 to $22 \%$. Measurements with land surface less than $15 \%$ were considered

18 representative of the lagoon surface. They represented $98 \%$ of the measurements

19 made in the 'lagoon' sector (Fig. 4a), but only 39\% of the measurements made in

20 the 'continental' sector and $91 \%$ of the measurements made in the 'lido' sector.

21 EC- and XLAS-derived sensible heat fluxes corresponded neither to the same

22 location nor to the same footprint size. XLAS measurements made with wind

23 blowing in the 'continental' sector (Fig. 4a) were partly representative of land

24 surface, while the EC station measurements are always representative of the 25 lagoon surface. These differences should be kept in mind when analyzing the 26 results.

\section{Sensitivity Analysis and Error Budget}

28 Several tests of sensitivity to input parameters are described below and 29 summarized in Table 3. They correspond to various steps of the processing as 30 described in part 2. All of them were performed on a 20-day dataset (9 to 28 June 312009 , hereafter referred to as 'the 20-day test period') representative of the mean 32 atmospheric conditions and of their variability. Finally, a detailed error budget is 33 presented. 
2 As stated in section 2.1.1, Eq. 1 was used to derive the $C_{n}^{2}$ values from the 3 intensity fluctuations measured by the XLAS. A sensitivity test was performed on

4 the test period of 20 days to assess whether using Eq. 3 rather than Eq. 1 to obtain

5 the $C_{n}^{2}$ values changed the final results (sensible heat fluxes). The mean 6 difference (Eq. 3 - Eq. 1) on $H$ is $0.81 \pm 1.62 \mathrm{~W} \mathrm{~m}^{-2}$, corresponding to a mean

7 relative difference (mean absolute value of the difference divided by the absolute

8 value of $H$ ) of $5.0 \pm 10.8 \%$ (Table 2). Here and in the following, all the figures

9 given with a ' \pm ' sign are standard deviations; i.e. RMS with respect to mean 10 values.

11 Note that a full error assessment of the $C_{n}^{2}$ signal measured by the XLAS should 12 include a comparison of the raw signal $\left(C_{n}^{2}\right)$ between at least two collocated 13 scintillometers. This was not done in this study.

\section{$14 \quad 4.2$ From $C_{n}^{2}$ to $C_{T}^{2}$}

15 The relationship between the structure parameter of the air refractive index and

16 the structure parameter of the temperature is given Eq. 5. It can be simplified to

17 Eq. 6 or to Eq. 7 depending on the mean value of the correlation coefficient 18 between the temperature and humidity fluctuations $R_{T q}$. To assess the effect of 19 taking this correlation $R_{T q}$ equal to zero in the final results (sensible heat flux 20 estimates), we performed a sensitivity test on the 20-day test period. The sensible 21 heat fluxes were processed using Eq. 7 (reference solution), the full relationship 22 between $C_{n}^{2}$ and $C_{T}^{2}$ derived from Eq. 5 with $R_{T q}$ estimated using eddy covariance 23 (full solution), and the classical relationship Eq. 6 (classical solution). The mean 24 difference (full minus reference solutions) was $0.17 \pm 0.48 \mathrm{~W} \mathrm{~m}^{-2}$, corresponding 25 to a mean relative difference of $1.0 \pm 1.8 \%$, while the mean difference (classical 26 minus reference solution) was $-3.35 \pm 2.54 \mathrm{~W} \mathrm{~m}^{-2}$, corresponding to a mean 27 relative difference of $21.0 \pm 8.8 \%$.

28 This relationship between $C_{n}^{2}$ and $C_{T}^{2}$ is very sensitive to the value of the Bowen 29 ratio used. As stated in section 2.2.2, the Bowen ratios obtained from a 30 computation using the gradient method were used to obtain final results as 31 independent as possible from EC-derived fluxes. However, the discrepancies 32 between the two Bowen ratio datasets are significant (see section 2.2.2, Fig. 1). To 
1 assess the uncertainties due to the use of gradient Bowen ratios rather than EC-

2 derived ones in this Eq. 7 (and this one only), we compared the sensible heat

3 fluxes obtained using the two datasets over the test period of 20 days (Table 3).

4 The mean difference (EC-derived minus gradient) is $-0.15 \pm 3.69 \mathrm{~W} \mathrm{~m}^{-2}$, with a

5 correlation coefficient of 0.97 and a mean relative difference of $11.0 \pm 22.2 \%$. We

6 also assessed the sensitivity of the sensible heat fluxes to a change of +0.2 on the

7 Bowen ratios, over the same period. The mean difference was $-1.28 \pm 6.47 \mathrm{~W} \mathrm{~m}^{-2}$

8 with a correlation coefficient of 0.91 and a mean relative difference of $13.1 \pm$ $948.3 \%$.

\section{$10 \quad 4.3$ From $C_{T}^{2}$ to Sensible Heat Flux}

11 The effect of using the air temperature rather than the virtual air temperature in 12 the XLAS processing (use of Eq.12) was assessed on the test dataset and proved 13 not to be significant. The mean difference (air temperature minus virtual air 14 temperature) was $0.10 \pm 0.07 \mathrm{~W} \mathrm{~m}^{-2}$, with a perfect correlation, corresponding to a 15 mean relative difference of $0.6 \pm 0.2 \%$. The effect of neglecting the buoyancy flux 16 effect in the temperature scale (Eq. 13) was estimated on the same dataset, and 17 shown to be significant. The mean difference (without humidity minus with 18 humidity) was $3.13 \pm 2.19 \mathrm{~W} \mathrm{~m}^{-2}$, with a correlation coefficient $R=0.99$ and a 19 mean relative difference of $29.0 \pm 31.0 \%$.

20 In addition to being part of Eq. 7 relating the structure parameter of the air 21 refractive index and the structure parameter of temperature, the Bowen ratio is 22 part of this Eq. 13. To assess the impact of using gradient Bowen ratios rather 23 than EC-derived ones in this Eq. 13 (and this one only), we compared the sensible 24 heat fluxes obtained using the two datasets over the test period of 20 days (Table 25 3). The mean difference (EC-derived minus gradient) is $-0.08 \pm 1.75 \mathrm{~W} \mathrm{~m}^{-2}$, with 26 a correlation coefficient of 0.99 and a mean relative difference of $4.0 \pm 15.9 \%$. 27 We also assessed the sensitivity of the sensible heat fluxes to a change of +0.2 on 28 the Bowen ratios, over the same period. The mean difference is negligible $(0.01 \pm$ $290.36 \mathrm{~W} \mathrm{~m}^{-2}$ with a perfect correlation and a mean relative difference of $1.5 \pm$ $30 \quad 2.2 \%$ ).

31 We then assessed the impact of using various Bowen ratio sources in the whole 32 processing (Eq.7 and Eq. 13). The mean difference obtained when using EC33 derived Bowen ratios rather than gradient ones is $-0.38 \pm 3.53 \mathrm{~W} \mathrm{~m}^{-2}$, with a 
1 correlation coefficient of 0.97 and a mean relative difference of $11.2 \pm 22.7 \%$ (see

2 Fig. 6, Table 3). A change of +0.2 on the Bowen ratios resulted in a mean

4 relative difference of $13.8 \pm 48.7 \%$ ). Doubling (respectively halving) these Bowen

5 ratios as shown Fig. 6 resulted in a mean difference of $0.93 \pm 1.44 \mathrm{~W} \mathrm{~m}^{-2}(1.09 \pm$

$6 \quad 1.52 \mathrm{~W} \mathrm{~m}^{-2}$ ), with a perfect correlation and a mean relative difference of $8.0 \pm$

$716.3 \%(10.9 \pm 15.1 \%)$. These tests show the very high sensitivity of the XLAS

8 processing results to the input Bowen ratio. The main influence of the Bowen

9 ratio comes from the (modified) relationship between $C_{n}^{2}$ and $C_{T}^{2}$ (Eq. 7).

10 A further step would be to adjust the Bowen ratio during the processing, as

11 suggested by McJannet et al. (2011).

12 A sensitivity test was performed on the 20-day test period to assess the impact of $13 z_{0}$ a priori values on the sensible heat flux estimates (Table 3). Using a priori 14 values of $10^{-3} \mathrm{~m}$ (respectively $10^{-5} \mathrm{~m}$ ) rather than $10^{-4} \mathrm{~m}$ for $z_{0}$ resulted in 15 negligible differences in the sensible heat flux (less than $1.0 \pm 5.9 \%$ mean relative 16 difference). We also compared (on the same test period) the roughness lengths 17 obtained in the XLAS processing with the bulk derived roughness lengths 18 (obtained using COARE 3.0). The mean difference (bulk minus XLAS-derived $z_{0}$ ) 19 was $-1.24 \times 10^{-6} \pm 7.87 \times 10^{-6} \mathrm{~m}$, with a correlation coefficient above 0.99 and a 20 mean relative difference of $5.5 \pm 13.3 \%$. We therefore conclude that computing $z_{0}$ 21 iteratively using Eq. 16 gives good results with respect to the bulk analysis.

22 To assess whether adjusting the roughness length iteratively (Eq. 16) had a 23 significant effect on the results or not, the scintillometry processing was 24 performed on the 20-day dataset with fixed $z_{0}$ inputs: using a mean fixed value for $25 z_{0}$ (the same value for every XLAS measurement, taken as the average of the $z_{0}$ 26 values computed from bulk) resulted in an $H$ mean difference of $-0.19 \pm 1.34 \mathrm{~W}$ $27 \mathrm{~m}^{-2}$ (fixed minus adjusted value; mean relative difference of $3.0 \%$ ). Using 28 individual fixed $z_{0}$ values for every XLAS measurement (computed from bulk) 29 resulted in a very low mean difference of $0.02 \pm 0.60 \mathrm{~W} \mathrm{~m}^{-2}$ (relative mean 30 difference of $1.0 \%$ ). Individual fixed $z_{0}$ values obtained from the EC analysis 31 resulted in a change of $-0.34 \pm 1.46 \mathrm{~W} \mathrm{~m}^{-2}$ (relative mean difference of $2.9 \%$ ). 32 Adjusting $z_{0}$ during the XLAS processing caused no significant changes in the 33 final results. 
1 The impact of using different universal functions $\varphi_{T}$ (section 2.3.4) for unstable

2 situations on the XLAS sensible heat flux estimates was assessed on the 20-day 3 test period. The function of Edson and Fairall (1998) was tested against those of 4 Andreas (1988b), Hill et al. (1992), Thiermann and Grassl (1992) and De Bruin 5 et al. (1993). The global results of this comparison are presented in Table 3 and

6 Figure 7. Mean relative differences with respect to the function of Edson and 7 Fairall (1998) reach as much as $18.3 \pm 5.2 \%$. The differences between the heat 8 fluxes computed using these functions roughly showed a proportionality 9 relationship, some functions (Andreas 1988b; De Bruin et al. 1993) 10 overestimating the results, while others (Hill et al. 1992; Thiermann and Grassl 11 1992) underestimated them.

12 Sensitivity tests were performed to assess the impact of using another momentum 13 stability function (Beljaars and Holtslag 1991) than the Businger-Dyer expression 14 (Eq. 18 and 19) on the sensible heat flux estimates. On the test dataset, the mean 15 difference was $0 \pm 0.37 \mathrm{~W} \mathrm{~m}^{-2}$, corresponding to a mean relative difference of 1.1 $16 \pm 2.0 \%$.

\section{$17 \quad$ 4.4 Error Budget}

18 The results of these various sensitivity tests are summarized in Table 3 . The main 19 possible error source appears to be due to using the scale parameter for 20 temperature $T *$ rather than the scale parameter including the buoyancy flux $T_{v^{*}}$, 21 with a mean relative difference of $29 \%$. The second possible error source is 22 related to the use of the classical relationship between the refractive index 23 structure parameter $C_{n}^{2}$ and the temperature structure parameter $C_{T}^{2}$ (Eq. 6) rather 24 than the relationship adapted to the conditions over water (Eq.7), with a mean 25 relative difference of $21 \%$ in the final result $H$. These two errors are specific to the 26 use of scintillometry above water and appear as both systematic biases (mean 27 difference above $3 \mathrm{~W} \mathrm{~m}^{-2}$ in absolute value) and random errors, as shown by the 28 high standard deviations (above $2 \mathrm{~W} \mathrm{~m}^{-2}$ ). The origin of these two main 29 uncertainties in the final results clearly shows that adapting the XLAS processing 30 scheme to take into account: 1) the humidity effect in the scale parameter for 31 temperature and 2) a correlation between the temperature and humidity 32 fluctuations closer to zero than to $+/-1$ was mandatory to ensure a good precision 33 in the final results. Computing the roughness length $z_{0}$ iteratively at every step of 
1 the processing, however, resulted in no change (1\% of mean relative difference) in

2 the final results, provided the bulk roughness length is used as a fixed input. Even

3 using a fixed mean value (mean bulk value) for $z_{0}$ resulted in only $3 \%$ mean

4 relative difference in the final results. It should be noted that this experiment on a

5 lagoon corresponds to very smooth surface state (roughness lengths less than $10^{-3}$

$6 \mathrm{~m})$.

7 Other significant uncertainties are not specific to an experiment over a lake. They

8 may result from the choice of the universal function $\varphi_{T}$. In particular, using the

9 universal function of De Bruin et al. (1993) rather than the Edson and Fairall

10 (1998) one changes the results by $18 \%$ (mean relative difference). Once again,

11 this error is the sum of a systematic bias (more than $3 \mathrm{~W} \mathrm{~m}^{-2}$ ) and random errors

12 (standard deviation of $2.66 \mathrm{~W} \mathrm{~m}^{-2}$ ). The Edson and Fairall (1998) function $\varphi_{T}$,

13 which was used in the processing, gave values for the final sensible heat flux

14 intermediate between other universal functions (see Fig. 3). Significant

15 uncertainties (up to $14 \%$ of mean relative difference) resulted from the choice of

16 the sources of the Bowen ratio used as an input to the XLAS processing (Eq. 7).

17 This dependency was exacerbated by the low values of this Bowen ratio over

18 water, as the Bowen ratio appears in the denominator in Eq. 7 and Eq. 13. This

19 uncertainty resulted more from random errors than systematic biases, as shown by

20 the high standard deviations (between 1.52 and $4.41 \mathrm{~W} \mathrm{~m}^{-2}$ ) and the moderate

21 mean differences. The final processing used the Bowen ratio values from a

22 gradient method computation. This is probably not the best possible choice, since

23 these computed values proved to be significantly different from the EC-derived

24 Bowen ratios (Figure 1), but it was desirable to obtain results fully independent of

25 the EC observations here.

26 Finally the total mean relative error may be estimated as the sum of the 27 uncertainties for which no clear choice or correction could be made, namely the 28 input Bowen ratio (mean relative difference of $14 \pm 49 \%$ ), the universal function

$29 \varphi_{T}$ (excluding De Bruin et al.'s (1993) function, mean relative difference of $5 \pm$ $305 \%$ ), and the formula for computing the refractive index structure parameter $C_{n}^{2}$

31 from raw data (mean relative difference of $5 \pm 11 \%$ ). If these three error sources

32 are considered as independent, the resulting final systematic error (sum of the

33 variances) is close to $16 \%$ for the XLAS processing, and the random error (sum of 
1 the RMS of the variances) is $50 \%$, largely due to the uncertainties on the Bowen

2 ratios.

\section{Validation of Fluxes}

4 As the XLAS processing was performed using input variables computed solely

5 from meteorological measurements made independently of the EC observations,

6 XLAS and EC outputs may be regarded as independent results. In the following,

7 we compare XLAS-derived sensible heat fluxes to those obtained using the EC

8 measurements.

9 Figure 8 shows a general comparison between the XLAS and EC sensible heat

10 flux, with a colour code corresponding to the wind direction. The regression

11 between the XLAS and EC estimates gives $H_{X L A S}=0.93 H_{E C}+0.96\left[\mathrm{~W} \mathrm{~m}{ }^{-2}\right]$,

12 meaning that the XLAS values are slightly underestimated relative to the EC ones.

13 The correlation coefficient $R$ is 0.832 , the mean difference $-0.62 \mathrm{~W} \mathrm{~m}^{-2}$, and the

14 RMS $9.53 \mathrm{~W} \mathrm{~m}^{-2}$. The agreement is thus good but, as the sensible heat flux values

15 over the Thau Lagoon are generally low $\left(19.7 \mathrm{~W} \mathrm{~m}^{-2}\right.$ and $22.8 \mathrm{~W} \mathrm{~m}^{-2}$ for the

16 XLAS estimates mean and median values respectively), the RMS of the difference

17 represents $73 \%$ of the flux value. The colour code used to represent the fluxes

18 (Fig. 8) clearly shows some systematic effects related to the wind direction. High

19 sensible heat flux values (above $40 \mathrm{~W} \mathrm{~m}^{-2}$ ) correspond to the 'continental' wind

20 sector (or wind blowing from inland, in yellow). They do not show any systematic

21 bias in the XLAS estimates with respect to EC-derived fluxes. Fluxes

22 corresponding to the 'lido' wind sector (wind blowing from the Mediterranean

23 Sea, in cyan) show an underestimation of the XLAS estimates with respect to the

24 EC estimates. Fluxes in red (north-east part of the 'lagoon' wind sector) indicate a

25 slight overestimation of the XLAS estimates with respect to the EC ones.

26 Differences between XLAS and EC estimates may result either from instrument

27 specificities (location or footprint differences as pointed out in section 3.5), from

28 theoretical concerns (deviation from MOST), or from internal uncertainties of the

29 two techniques. In the following, we first investigate whether the observed

30 discrepancies may be explained by deviations from MOST, then we focus on

31 discrepancies that may be related to either location or footprint differences. 


\section{$1 \quad 5.1$ Deviations from MOST}

2 MOST is the theory underlying both the XLAS processing and bulk computation.

3 It is based on several hypotheses concerning the atmospheric surface layer, viz.:

4 [1] steady state conditions; [2] sufficiently developed turbulence; [3] horizontal

5 homogeneity of the air flow; [4] turbulent fluxes varying little with height.

6 If one or more of the above assumptions are not fulfilled, then MOST conditions

7 are not met: the XLAS processing scheme and bulk computation rely on non-

8 verified conditions and the sensible heat fluxes estimated using either the XLAS

9 or the bulk algorithm may be biased or affected by random errors when compared

10 to EC measurements.

11 Two of these assumptions - steady state conditions and fully developed 12 turbulence ([1] and [2]) - are also used within the EC processing scheme, and 13 their validity is verified through the quality control of the TK2 software. As 14 recommended by Mauder and Foken (2004), only the data with overall flags of 1, 152 , or 3 were kept for the analysis. This first selection should thus guarantee that 16 assumptions [1] and [2] are met for the dataset on which the present study relies.

17 Assumption [3], corresponding to horizontally homogeneous conditions within 18 the measurement footprints is probably not always met, especially for wind 19 directions in the 'continental' and 'lido' sectors. The geographical situation of the 20 lagoon enclosed between small hills and a 'lido' is favourable to air mass 21 advection from inland that may result in non-homogeneous conditions within the 22 XLAS footprint. This non-homogeneity may affect the measured parameter 23 (structure parameter for refractive index $C_{n}^{2}$ ) or the physical value of the sensible 24 heat flux. As a result, MOST is not fulfilled, the XLAS processing scheme relies 25 on non-verified conditions, and the sensible heat fluxes estimated using the XLAS 26 may be biased or affected by random errors.

27 The failure of assumption [4] (turbulent fluxes almost constant with height within 28 the atmospheric surface layer) may correspond, for instance, to the formation of 29 an internal boundary layer due to the roughness change between the land surface 30 and the lagoon surface, or to the formation of a wave boundary layer due to the 31 surface state of the lagoon. Measurements of significant wave heights during the 32 experiment gave a mean value of $0.020 \mathrm{~m}$, with a maximum value of $0.271 \mathrm{~m}$, 33 showing that there is almost no wave field at the lagoon surface. We have, 
1 however, no further measurements providing information on a possible internal

2 boundary layer.

3 In the following, we attempt to quantify the level of agreement of the atmospheric

4 conditions with MOST requirements, using the EC measurements as a reference

5 dataset. As bulk computations rely on MOST, and as the 'slow' parameter

6 measurements needed are exactly collocated with the EC measurements (both

7 recorded at the EC-Marseillan station), we chose to quantify the deviations from

8 MOST by comparing the bulk estimates and EC measurements. The results of this

9 comparison are representative of MOST fulfilment at Marseillan, but probably not

10 within the XLAS source area as: i) the location is not the same, and conditions

11 could therefore be different; ii) the respective sizes of the footprint areas for the

12 XLAS and EC estimates are very different.

13 A global comparison between the EC sensible heat fluxes and that computed 14 using the COARE 3.0 software is provided in Figure 9a. The correlation 15 coefficient $(R=0.850)$ and the RMS $=9.18 \mathrm{~W} \mathrm{~m}^{-2}$ are slightly better than those 16 obtained between XLAS and EC measurements. The regression between bulk 17 estimates and EC values is $H_{b u l k}=0.98 H_{E C}-0.06\left[\mathrm{~W} \mathrm{~m}^{-2}\right]$, showing that the bulk 18 fluxes slightly underestimate the EC values. There is no mean bias. The general 19 agreement is then very good but with some scatter close to the level obtained 20 when comparing the two measurement datasets. It is therefore difficult to 21 conclude on the general fulfilment of MOST at the Marseillan station using the 22 EC estimates. The colour patterns that were observed in the XLAS-EC flux 23 comparison (Fig. 8) are still present, and even more clear, in Figure 9a, 24 confirming that they correspond to systematic effects.

25 These systematic deviations between the bulk fluxes and EC measurements may 26 come either from atmospheric physical effects (non-homogeneity) leading to 27 discrepancies between the actual conditions and that corresponding to MOST, or 28 from inaccuracies in the EC estimates. To check the latter hypothesis, the same 29 comparison between EC results and bulk computation was made using only the 30 highest quality EC measurements (flag = 1, see Table 2). The very same patterns 31 were observed with striking clarity (Figure 9b), indicating that these deviations 32 are more probably due to the atmospheric conditions than to the quality of the EC 33 measurements. As such a quality flag is supposed to correspond to both steady 34 state conditions and well developed turbulence, these discrepancies between 
1 observations and theory should be related either to horizontal non-homogeneities

2 (assumption [3]) or to variations of the turbulent fluxes with height (assumption

3 [4]). In the following, we use the footprint analysis of the XLAS measurements to

4 select - in the EC and bulk flux datasets - the observations corresponding to the

5 most homogeneous conditions, that is to say atmospheric conditions that best

6 fulfil at least three of the underlying MOST assumptions.

7 Using the results of the previous XLAS footprint analysis, we now consider only

8 the data in which at least $85 \%$ of the area corresponds to lagoon surface and with

9 wind direction in the 'lagoon' sector, which represent $21 \%$ of the total number of

10 measurements. A comparison between the EC-derived and bulk computed fluxes

11 obtained using this reduced dataset (Figure 10) shows a very good correlation $(R$

$12=0.912)$, higher than that obtained for the full dataset $(R=0.850)$, and a reduced

$13 \mathrm{RMS}$ of $6.06 \mathrm{~W} \mathrm{~m}^{-2}$ (RMS $=9.18 \mathrm{~W} \mathrm{~m}^{-2}$ previously). The linear regression now

14 reads $H_{b u l k}=1.01 H_{E C}+1.67$, and there is a positive bias between the two datasets

15 of $1.85 \mathrm{~W} \mathrm{~m}^{-2}\left(H_{\text {bulk }}-H_{E C}\right)$. No clear patterns in connection with the wind sector

16 (north-eastward vs. south-westward) are visible in Fig. 10. Focusing on

17 homogeneous conditions by selecting the data representative of the lagoon surface

18 thus significantly reduces the deviations from MOST, as shown by the improved

19 agreement between the EC fluxes and bulk estimates.

\subsection{Footprint and Location Differences}

21 As no representative measurements were performed near the middle of the XLAS 22 path, no direct comparison of the XLAS estimates with the bulk computation was 23 possible. We focus here on the comparison between XLAS estimates (MOST24 dependent, not collocated) and EC measurements. We used the same methodology 25 as previously on the whole dataset to check whether selecting only the 26 measurements corresponding to the theoretically most homogeneous conditions 27 improved the agreement between the XLAS- and EC-derived fluxes (Figure 11). 28 The agreement between XLAS- and EC-derived fluxes was better than when all 29 the measurements were considered. Keeping only the data with more than $85 \%$ of 30 the footprint on the lagoon surface and wind direction in the lagoon sector indeed 31 reduced the dispersion between the XLAS and the EC estimates. As previously, 32 no systematic effect connected with the wind direction (north-eastward vs. south33 westward) was observed. The best linear regression between the XLAS and eddy 
1 covariance estimates was $H_{X L A S}=0.96 H_{E C}+3.29\left[\mathrm{~W} \mathrm{~m}^{-2}\right]$, with a large mean bias

2 of $2.65 \mathrm{~W} \mathrm{~m}^{-2}$ and an RMS of $8.68 \mathrm{~W} \mathrm{~m}^{-2}$. The systematic part of the 3 discrepancies was higher $\left(2.65 \mathrm{~W} \mathrm{~m}^{-2}\right.$ for the selection vs. $-0.62 \mathrm{~W} \mathrm{~m}^{-2}$ for the full

4 dataset) but with a significantly reduced random part $\left(8.68 \mathrm{~W} \mathrm{~m}^{-2}\right.$ for the selection

5 vs. $9.53 \mathrm{~W} \mathrm{~m}^{-2}$ for the full dataset). The correlation between the two datasets was

6 quite good $(R=0.807)$ but lower than what was obtained when considering the

7 whole dataset.

8 Interpreting the systematic discrepancy of $2.65 \mathrm{~W} \mathrm{~m}^{-2}$ is not straightforward.

9 However, part of it is probably due to the disagreement noted previously between

10 the actual conditions (illustrated by the EC-derived fluxes) and MOST

11 requirements (on which the derivation of the sensible heat flux from XLAS

12 measurements relies). In particular, even when the measurements were selected to

13 be representative of the lagoon surface, non-homogeneity in the atmospheric

14 conditions could occur in connection with the advection of cold or warm air from

15 inland or mild air from the Mediterranean. Another part of the discrepancy is

16 probably due to observing and/or processing errors of the XLAS itself (estimated

17 to be $16 \%$, section 4.4 ), and of the eddy covariance method.

18 The last part of this disagreement may be explained by the difference of location

19 of the two instruments. As shown by the bathymetry map (Fig. 5), the XLAS

20 source area includes zones of various depth, ranging $2 \mathrm{~m}$ close to the shores to 10

$21 \mathrm{~m}$ near the middle of the lagoon. The water depth in the EC source area is much

22 more uniform and close to $4 \mathrm{~m}$. This may result in different thermal behaviour of

23 the lagoon at the two locations, and then in discrepancy in the sensible heat flux.

24 The discrepancy due to horizontal remoteness may be reinforced (or partly

25 compensated) by the measurement height difference (6 $\mathrm{m}$ for the EC station, 12.6

$26 \mathrm{~m}$ for the XLAS): Mahrt et al. (1998) indeed noted a heat flux difference of up to

$2750 \%$ between the 3-m and 10-m level measurements during RASEX, in case of

28 cold air advection.

\section{Conclusion}

30 For the first time, an Extra Large Aperture Scintillometer (XLAS) performed 31 reliably over water for a long period of time.

32 We expose here how the algorithms classically used over land surfaces to derive

33 sensible heat fluxes from scintillation measurements can be adapted to obtain air- 
1 sea or air-lake fluxes. The main adaptations of the processing schemes concern (i)

2 the use of a scale parameter for temperature including a humidity correction

3 (rather than a temperature scale parameter without humidity), and (ii) the use of a

4 correlation coefficient between temperature and humidity fluctuations close to

5 zero as in Odhiambo et al. (2009). Not accounting for these effects (typical of the

6 lagoon environment) may result in 20 to $30 \%$ systematic errors in the sensible

7 heat flux estimates. In contrast, using a fixed mean value for the roughness length,

8 rather than adjusting this value during the processing (as we did), results in minor

9 changes in the results (3\% or less). A full error budget of the XLAS processing,

10 including several sensitivity tests, showed that the final results are mainly

11 dependent on the choice of the Bowen ratio used as a fixed input in the

12 processing. A further improvement of the method (beyond the scope of this study)

13 would be to test the iterative Bowen ratio adjustment suggested recently by

14 McJannet et al. (2011). Another processing parameter impacting the final results

15 is the universal similarity function $\varphi_{T}$. The function of Edson and Fairall (1998)

16 used here gave intermediate results among the different universal functions

17 reported in the literature. Finally, the systematic error level due to XLAS

18 processing uncertainties amounts $16 \%$, with a random error of $\approx 50 \%$.

19 The comparison of the results with nearby EC fluxes is incomplete due to lack of

20 real collocation, as logistical constrains prevailed in the choice of instrument

21 location. Nevertheless, the general agreement between the two estimated sensible

22 heat fluxes during the whole experiment (117 days) is rather good, and

23 comparable to what could be obtained over heterogeneous land surfaces or on the

24 open sea from other instruments: the regression equation for the whole dataset is

$25 H_{X L A S}=0.93 H_{E C}+0.96\left[\mathrm{~W} \mathrm{~m}{ }^{-2}\right]$, with a correlation coefficient of 0.832 and an

26 RMS of $9.53 \mathrm{~W} \mathrm{~m}^{-2}$. The agreement between the EC-derived and XLAS fluxes is

27 only slightly lower than that obtained between EC measurements and bulk fluxes

28 computed using collocated atmospheric/hydrological mean parameters $(\mathrm{RMS}=$

$299.18 \mathrm{~W} \mathrm{~m}^{-2}$ ). LAS can thus be considered as a valuable technique for assessing

30 sensible heat fluxes at sea with an accuracy better than $10 \mathrm{~W} \mathrm{~m}^{-2}$.

31 As shown by the comparison of the collocated EC-derived and bulk computed

32 fluxes, some of the discrepancies between XLAS and EC fluxes are due to

33 deviations from MOST. If only the data representative of the lagoon surface are

34 used, the discrepancies between the EC-derived and bulk computed fluxes fall 
1 from 9.18 to $6.06 \mathrm{~W} \mathrm{~m}^{-2}$ (RMS) with a bias of $1.85 \mathrm{~W} \mathrm{~m}^{-2}$. Using the same

2 selected dataset, the agreement between the XLAS fluxes and the EC-derived

3 fluxes improves, the RMS being reduced to $8.68 \mathrm{~W} \mathrm{~m}^{-2}$. Keeping only the

4 measurements representative of more homogeneous conditions thus proves to

5 provide better results.

6 The remaining discrepancies between the XLAS and EC sensible heat fluxes are

7 difficult to interpret. They may be related to the difference in the instrument

8 locations (several kilometres), the difference between the measurement heights (a

9 few metres), and to the respective sizes of the source areas, which differ by

10 several orders of magnitude: the XLAS footprint, in particular, is large enough to

11 include various surface conditions. This is similar to horizontal effects that can

12 affect lakes as pointed out by Elo (2007) and proved to be difficult to take into

13 account for modelling studies.

14 These first results need to be confirmed with perfectly collocated XLAS and EC

15 measurements, as our comparison clearly suffers from the distinct measurement

16 locations, the impact of which is amplified by the footprint differences. In

17 addition, an interesting perspective of this study could be to perform the same

18 kind of comparisons in an open sea environment, including strong winds and

19 various sea states (especially swell).

20 Acknowledgements

21 The authors are grateful to the Ifremer Sète technical team, to A. Manteghetti, IUT de Chimie,

22 Université de Montpellier 2, to O. Filippi, Pépinières Filippi Loupian, and to M. Cazanova for

23 their support during the field experiment and for their authorization to set up the instrumentation.

24 Thanks to G. Pellecuer and C. Dupressoir, Météo France, for their contribution to meteorological

25 measurements. We thank R. Verney, Ifremer, for providing spectral wave measurements. We are

26 grateful to P. Le Moigne, CNRM, for providing the Thau Lagoon bathymetry data. Most of the

27 graphics were made using the GMT package of Wessel and Smith (1998). We thank H.P. Schmid,

28 Indiana University, for providing the FSAM/SAM software. The Thau Lagoon and surroundings

29 map was downloaded from the (C) Google Maps service, part of information are provided by

30 Géoroute @ 2008 IGN France and/or @ 2008 IGN France. 


\section{References}

2 Andreas EL (1988a) Two-wavelength method of measuring path-averaged turbulent surface heat

3 fluxes. J Atmos Ocean Technol 6: 280-292

4 Andreas EL (1988b) Estimating $C_{n}^{2}$ over snow and sea ice from meteorological data. J Opt Soc

5 Amer 5:481-495

6 Beljaars ACM, Holtslag AAM (1991) Flux parameterization over land surfaces for atmospheric

7 models. J Appl Meteorol 30:327-341

8 Beyrich F, De Bruin HAR, Meijninger WML, Schipper JW, Lohse H (2002) Results from one

9 year continuous operation of a large aperture scintillometer over a heterogeneous land surface.

10 Boundary-Layer Meteorol 105:85-97

11 Bourras D, Weill A, Caniaux G, Eymard L, Bourlès B, Letourneur S, Legain D, Key E, Baudin F,

12 Piguet B, Traullé O, Bouhours G, Sinardet B, Barrié J, Vinson J, Boutet F, Berthod C, Clémençon

13 A (2009) Turbulent air-sea fluxes in the Gulf of Guinea during the AMMA experiment. J Geophys

14 Res 114, C04014 doi:10.1029/2008JC004951

15 De Bruin HAR, Kohsiek W, van den Hurk BJJM (1993) Verification of some methods to

16 determine the fluxes of momentum, sensible heat, and water vapour using standard deviation and

17 structure parameter of scalar meteorological quantities. Boundary-Layer Meteorol 63:231-257

18 De Bruin HAR, van den Hurk BJJM, Kohsiek W (1995) The scintillation method tested over a dry

19 vineyard area. Boundary-Layer Meteorol 76:25-40

20 Edson JB, Fairall CW (1998) Similarity relationships in the marine atmospheric surface layer for

21 terms in the TKE and scalar variance budgets. J Atmos Sci 55:2311-2328

22 Elo PAR (2007) The energy balance and vertical thermal structure of two small boreal lakes in

23 summer. Boreal Env Res 12:585-600

24 Ezzahar J, Chehbouni A (2009) The use of scintillometry for validating aggregation schemes over

25 heterogeneous grids. Agric Forest Meteorol 149:2098-2109 doi:10.1016/j.agrformet.2009.09.004

26 Ezzahar J, Chehbouni A, Hoedjes J, Ramier D, Boulain N, Boubkraoui S, Cappelaere B, Descroix

27 L, Mougenot B, Timouk F (2009) Combining scintillometer measurements and an aggregation

28 scheme to estimate area-averaged latent heat flux during the AMMA experiment. J Hydrol

29 375:217-226 doi:10.1016/j.jhydrol.2009.01.010

30 Fairall CW, Bradley EF, Hare JE, Grachev AA, Edson JB (2003) Bulk parameterization of air-sea

31 fluxes: updates and verification for the COARE algorithm. J Clim 16:571-591

32 Foken T, Skeib G, Richter SH (1991) Dependence of the integral turbulence characteristics on the

33 stability of stratification and their use for Doppler-Sodar measurements. Z Meteorol 41:311-315

34 Foken T, Wichura B (1996) Tools for quality assessment of surface-based flux measurements.

35 Agric Forest Meteorol 78:83-105

36 Foken T, Goeckede M, Mauder M, Mahrt L, Amiro BD, Lunger JW (2004) Post-field data quality

37 control. In: Lee X et al. (eds) Handbook of Micrometeorology: a guide for surface flux

38 measurement and analysis. Kluwer Dordrecht 181-208

39 Frehlich RG, Ochs GR (1990) Effects of saturation on the optical scintillometer. Appl Optics

$40 \quad 29: 548-553$ 
Hartogensis OK, Watts CJ, Rodriguez J-C, De Bruin HAR (2003) Derivation of an effective height for scintillometers: La Poza experiment in Northwest Mexico. J Hydrol 4:915-928

3 Hill RJ, Clifford SF (1981) Theory of saturation of optical scintillation by strong turbulence for 4 arbitrary refractive-index spectra. J Opt Soc Am 71:675-686

5 Hill RJ, Ochs GR, Wilson JJ (1992) Measuring surface-layer fluxes of heat and momentum using

6 optical scintillation. Boundary-Layer Meteorol 58:391-408

7 Højstrup J (1981) A simple model for the adjustment of velocity spectra in unstable conditions

8 downstream of an abrupt change in roughness and heat flux. Boundary-Layer Meteorol 21:341-

9356

10 Kaimal JC, Wyngaard JC, Izumi Y, Coté OR (1972) Spectral characteristics of surface layer

11 turbulence. Quat J Meteorol Soc 9:563-589

12 Kaimal JC, Finnigan JJ (1994) Atmospheric boundary layer flows: their structure and

13 measurement. Oxford University Press, New York, NY, 289 pp

14 Kipp \& Zonen (2007) LAS \& X-LAS, (Extra) Large Aperture Scintillometer Instruction Manual.

15 Kleissl J, Gomez J, Hong S-H, Hendrickx JMH, Rahn T, Defoor WL (2008) Large Aperture

16 Scintillometer intercomparison study. Boundary-Layer Meteorol 128:133-150

17 doi:10.1007/s10546-008-9274-1

18 Kleissl J, Watts CJ, Rodriguez JC, Naif S, Vivoni ER (2009) Scintillometer intercomparison study

19 - continued. Boundary-Layer Meteorol 130:437-443 doi:10.1007/s10546-009-9352-z

20 Kohsiek W, Meijninger WML, Moene AF, Heusinkveld BG, Hartogensis OK, Hillen WCAM, De

21 Bruin HAR (2002) An Extra Large Aperture Scintillometer for long range applications. Boundary-

22 Layer Meteorol 105:119-127

23 Kohsiek W, Meijninger WML, De Bruin HAR, Beyrich F (2006) Saturation of the Large Aperture

24 Scintillometer. Boundary-Layer Meteorol 121:111-126 doi:10.1007/s10546-005-9031-7

25 Kohsiek W, Liebethal C, Foken T, Vogt R, Oncley SP, Bernhofer C, De Bruin HAR (2007) The

26 energy balance experiment EBEX-2000. Part III: Behaviour and quality of radiation

27 measurements. Boundary-Layer Meteorol 123:55-75

28 Lagouarde JP, Irvine M, Bonnefond J-M, Grimmond CSB, Long N, Oke TR, Salmond JA, Offerle

29 B (2006) Monitoring the sensible heat flux over urban areas using Large Aperture Scintillometry:

30 case study of Marseille City during the Escompte experiment. Boundary-Layer Meteorol 118:449-

31476 doi:10.1007/s10546-005-9001-0

32 Liu H, Peters G, Foken T (2001) New equations for sonic temperature variance and buoyancy heat

33 flux with an omnidirectional sonic anemometer. Boundary-Layer Meteorol 100:459-468

34 Ludi A, Beyrich F, Matzler C (2005) Determination of the turbulent temperature-humidity

35 correlation from scintillometric measurements. Boundary-Layer Meteorol 117:525-550

36 doi:10.1007/s10546-005-1751-1

37 Mahrt L, Vickers D, Edson J, Sun J, Hojstrup J, Hare J, Wilczak JM (1998) Heat flux in the

38 coastal zone. Boundary-Layer Meteorol 86:421-446

39 Mauder M, Foken T (2004) Documentation and instruction manual of the eddy covariance

40 software package TK2. Arbeitsergebn, Univ Bayreuth, Abt Mikrometeorol, ISSN 1614-8916. 26-

4142 
1 Mauder M, Foken T (2006) Impact of post-field data processing on eddy covariance flux estimates

2 and energy balance closure. Z Meteorol 15:597-609

3 Mauder M, Foken T, Clement R, Elbers J, Eugster W, Gruenwald T, Heusinkveld B, Kolle O

4 (2008) Quality control of CarboEurope flux data - Part 2: Inter-comparison of eddy-covariance

5 software. Biogeosci 5:451-462

6 McJannet DL, Cook FJ, McGloin RP, McGowan HA, Burn S (2011) Estimation of evaporation

7 and sensible heat flux from open water using a large-aperture scintillometer. Water Resour Res 47:

8 W05545 doi:10.1029/2010WR010155

9 Meijninger WML, Hartogensis OK, Kohsiek W, Hoedjes JCB, Zuurbier RM, De Bruin HAR

10 (2002) Determination of area-averaged sensible heat flux with a Large Aperture Scintillometer

11 over a heterogeneous surface - Flevoland field experiment. Boundary-Layer Meteorol 105:37-62

12 Moene AF (2003) Effects of water vapour on the structure parameter of the refractive index for

13 near-infrared radiation. Boundary-Layer Meteorol 107:635-653

14 Moene AF, Meijninger WML, Hartogensis OK, Kohsiek W, De Bruin HAR (2004) A review of

15 the relationships describing the signal of a Large Aperture Scintillometer. Internal Report 2004/2,

16 Meteorology and Air Quality Group, Wageningen University. http://www.met.wau.nl. Accessed

$17 \quad 13$ February 2011

18 Moene AF, Beyrich F, Hartogensis OK (2009) Developments in scintillometry. Bull Am Meteorol

19 Soc doi:10.1175/2008BAMS2672.1

20 Moore CJ (1986) Frequency response corrections for eddy correlation systems. Boundary-Layer

21 Meteorol 37:17-35

22 Ochs GR, Hill RJ (1990) A study of factors influencing the calibration of optical $C_{n}^{2} C$ meters,

23 NOAA Technical Memorandum ERL WPL-106

24 Odhiambo GO, Savage MJ (2009) Sensible heat flux by Surface Layer Scintillometry and Eddy

25 Covariance over a mixed grassland community as affected by Bowen ratio and MOST

26 formulations for unstable conditions. J Hydromet 10:479-492 doi:10.1175/2008JHM1008.1

27 Paulson CA (1970) The mathematical representation of wind speed and temperature profiles in the

28 unstable boundary layer. J Appl Meteorol 9:857-861

29 Schmid HP (1994) Source areas for scalars and scalar fluxes. Boundary-Layer Meteorol 67:293-

30318

31 Schotanus P, Nieuwstadt FTM, De Bruin HAR (1983) Temperature measurement with a sonic

32 anemometer and its application to heat and moisture fluctuations. Boundary-Layer Meteorol

$33 \quad 26: 81-93$

34 Smith SD (1988) Coefficients for sea surface wind stress, heat flux, and wind profiles as a function

35 of wind speed and temperature. J Geophys Res 93(C12):15467-15472

36 Sun J, Vandemark D, Mahrt L, Vickers D, Crawford T, Vogel C (2001) Momentum transfer over

37 the coastal zone. J Geophys Res 106(D12):12437- 12448

38 Thiermann V, Grassl H (1992) The measurements of turbulent surface-layer fluxes by use of

39 bichromatic scintillation. Boundary-Layer Meteorol 58:367-389 
1 Van Kesteren B, Hartogensis OK (2011) Analysis of the systematic errors found in the Kipp \&

2 Zonen large-aperture scintillometer. Boundary-Layer Meteorol 138:493-509 doi:10.1007/s10546-

$3 \quad 010-9564-2$

4 Wang T, Ochs GR, Clifford SF (1978) A saturation-resistant optical scintillometer to measure $C_{n}^{2}$.

5 J Opt Soc Am 68:334-338

6 Webb EK, Pearman GI, Leuning R (1980) Correction of the flux measurements for density effects

7 due to heat and water vapour transfer. Quat J Roy Meteorol Soc 106:85-100

8 Weill A, Eymard L, Caniaux G, Hauser D, Planton S, Dupuis H, Brut A, Guerin C, Nacass P,

9 Butet A, Cloché S, Pedreros R, Durand P, Bourras D, Giordani H, Lachaud G, Bouhours G (2003)

10 Toward a better determination of turbulent air-sea fluxes from several experiments. J Clim 16:600-

11618

12 Wesely ML (1976) The combined effect of temperature and humidity fluctuations on refractive

13 index. J Appl Meteorol 15:43-49

14 Wessel P, Smith WHF (1998) New, improved version of the Generic Mapping Tools Released.

15 EOS Trans AGU 79:579

16 Wilczak JM, Oncley SP, Stage SA (2001) Sonic anemometer tilt correction algorithms. Boundary-

17 Layer Meteorol 99:127-150

18 Yelland MJ, Moat BI, Taylor PK, Pascal RW, Hutchings J, Cornell VC (1998) Wind stress

19 measurements from the open-ocean corrected for airflow distortion by the ship. J Phys Oceanog

$20 \quad 28: 1511-1526$

21 Zeweldi DA, Gebremichael M, Wang J, Sammis T, Kleissl J, Miller D (2010) Intercomparison of

22 sensible heat flux from Large Aperture Scintillometer and Eddy Covariance methods: field

23 experiment over a homogeneous semi-arid region. Boundary-Layer Meteorol doi:10.1007/s10546-

$24 \quad 009-9460-9$

25 
1 Figure 1: Histograms of the Bowen ratios computed using the gradient method (solid grey) and

2 derived from the eddy covariance measurements (open black).

3 Figure 2: Map of the Thau Lagoon (copyright Google Maps) with the XLAS transmitter and 4 receiver locations, the EC Marseillan station (yellow dot) and Marseillan, Sète, and Crique

5 Meteorological Stations (MS, red dots).

6 Figure 3: (a) XLAS transmitter; the black arrow indicates the XLAS receiver approximate

7 location; (b) EC measurement mast with a sonic anemometer and an Infrared Gas Analyzer. Note

8 the EC-collocated meteorological station providing 'slow' atmospheric parameter measurements.

9 Figure 4: Mean meteorological and hydrological conditions as derived from Marseillan station

10 measurements. (a) Wind rose showing the different wind sectors in Marseillan (see text). The

11 black arrow indicates the XLAS path orientation; (b) Histogram (number of observations) of the

$1210-\mathrm{m}$ wind velocity $\left(\mathrm{m} \mathrm{s}^{-1}\right)$; (c) Histogram (number of observations) of the air temperature minus

13 lagoon temperature $\left({ }^{\circ} \mathrm{C}\right)$.

14 Figure 5: Footprints computed for XLAS and EC measurements, (a) for wind blowing across the

15 XLAS path, either from south-west (solid lines) or from north-east (dashed lines); (b) for wind

16 blowing along the XLAS path, either from north-west (solid lines) or from south-east (dashed

17 lines). The different contours correspond to 50\% (green), 70\% (blue), 80\%(red), and 90\% (black)

18 source area, the grey scale indicates the depth (m).

19 Figure 6: Outcomes of tests (performed over a 20-day period) of the XLAS processing sensitivity

20 to Bowen ratio input values: resulting sensible heat flux values ( $H$, vertical axis) obtained when

21 the original Bowen ratio is multiplied by a factor 2 (red circles) or replaced by that derived from

22 the eddy covariance method (black crosses) with respect to the sensible heat fluxes obtained with

23 the original Bowen ratio (horizontal axis).

24 Figure 7: Results of tests of the XLAS processing sensitivity to the universal function $\varphi_{T}$, with 25 respect to the Edson and Fairall (1998) universal function (E \& F 1998): Andreas (1988b) (A

26 1988, black crosses), De Bruin et al. (1993) (DB 1993, red circles), Hill et al. (1992) (H 1992, blue

27 diamonds), and Thiermann and Grassl (1992) (T \& G 1992, green triangles).

28 Figure 8: Comparison of the sensible heat flux assessed using the XLAS ( $y$-axis) and the EC

29 station ( $x$-axis), in $\mathrm{W} \mathrm{m}^{-2}$. The colour code corresponds to the wind direction, yellow to the

30 'continental' sector, cyan to the 'lido' sector, and red and green to the 'lagoon' sector. The black

31 arrow on the scale indicates the XLAS path orientation. The dash-dotted line indicates the best

32 regression line, and the dotted lines the RMS limits.

33 Figure 9: Comparison of the sensible heat flux computed using the COARE 3.0 bulk algorithm and 34 atmospheric parameters measured in Marseillan ( $y$-axis) and that derived from the EC station ( $x$ 35 axis), in $\mathrm{W} \mathrm{m}^{-2}$, (a) whole dataset; (b) data with EC quality flag $=1$ only. Colour code: same as

36 Figure 8 . The black arrow on the scale indicates the XLAS path orientation. The dash-dotted line

37 indicates the best regression line, and the dotted lines the RMS limits. 
1 Figure 10: Same as Figure 9a, but for data with at least $85 \%$ of the source area on the lagoon

2 surface and wind direction in the 'lagoon' sector (north-east and south-west).

3 Figure 11: Same as Figure 8, but for data with at least $85 \%$ of the source area on the lagoon

4 surface and wind direction in the 'lagoon' sector (north-east and south-west).

5 


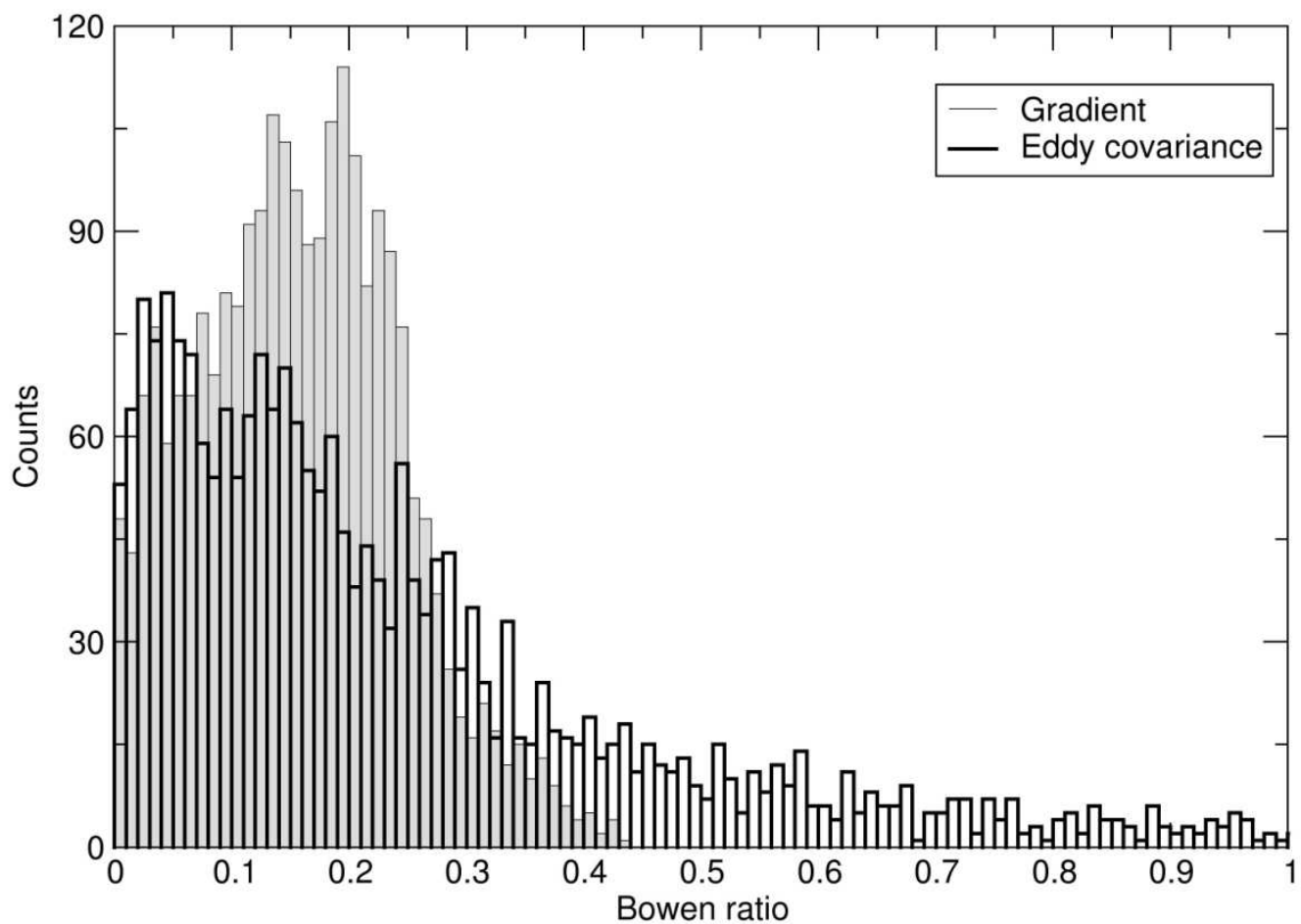

3

4

Figure 1

5

6 


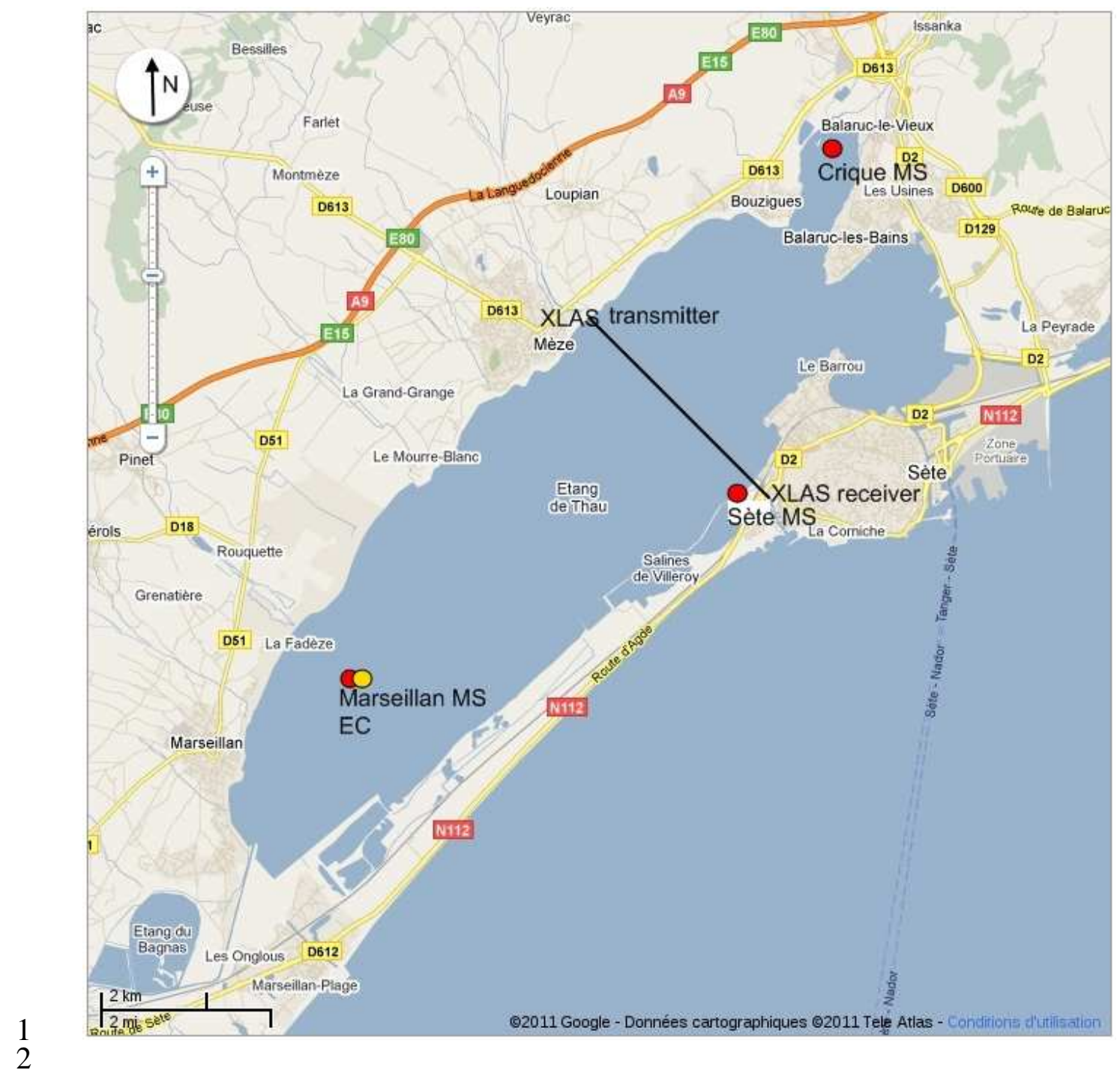




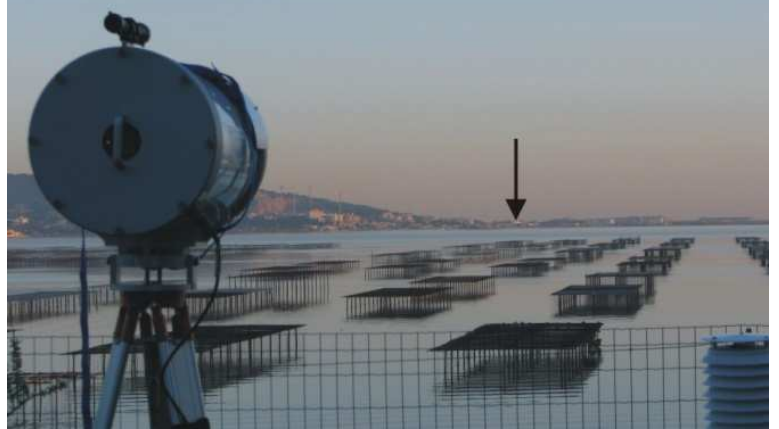

4

Figure $3 a$

6

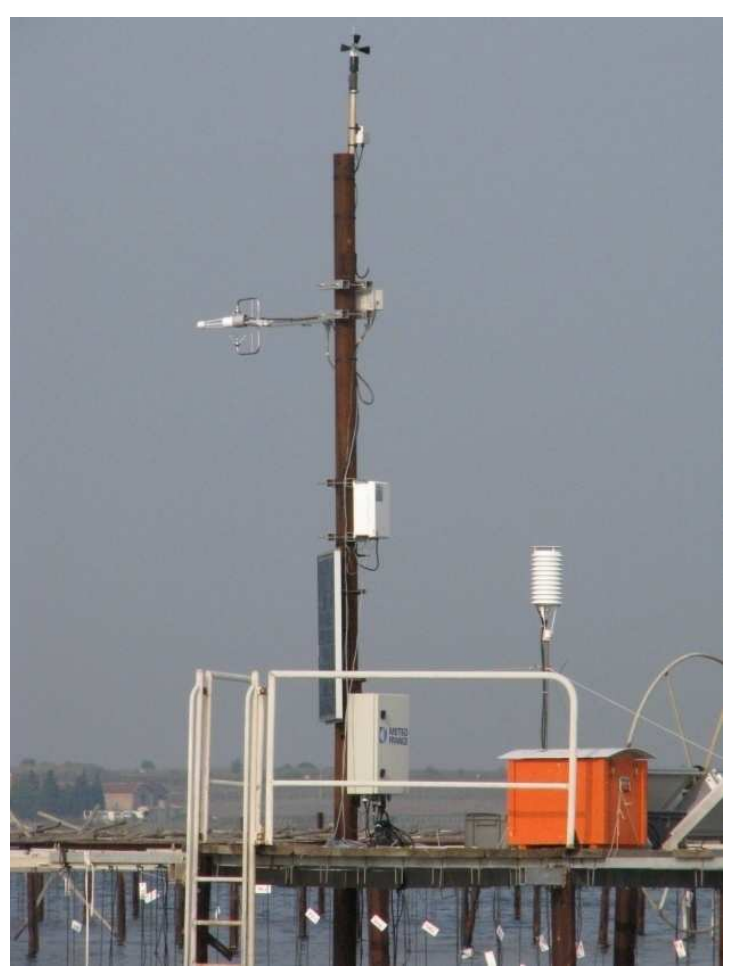

Figure $3 b$ 


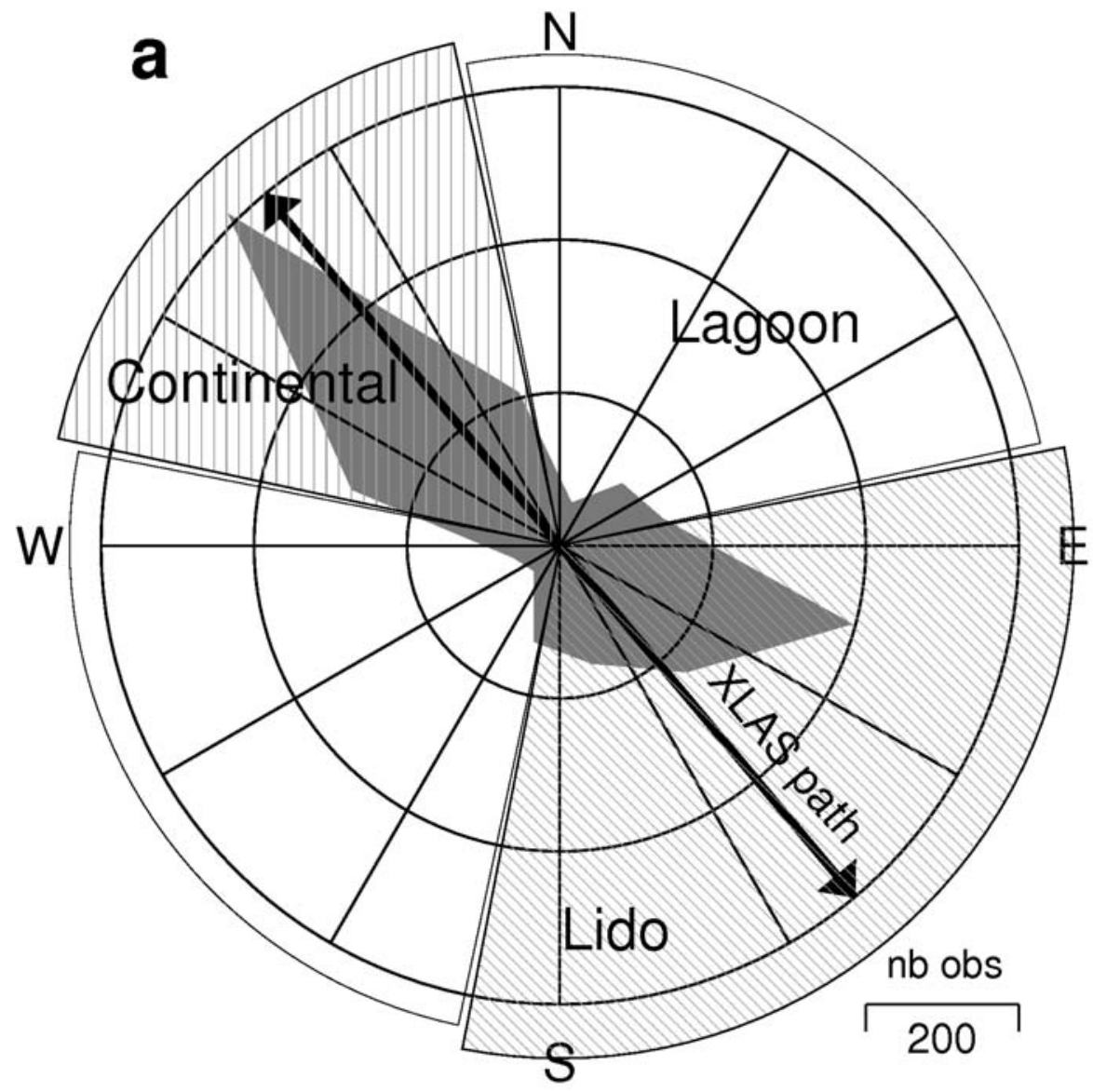

2

Figure 4a

4 


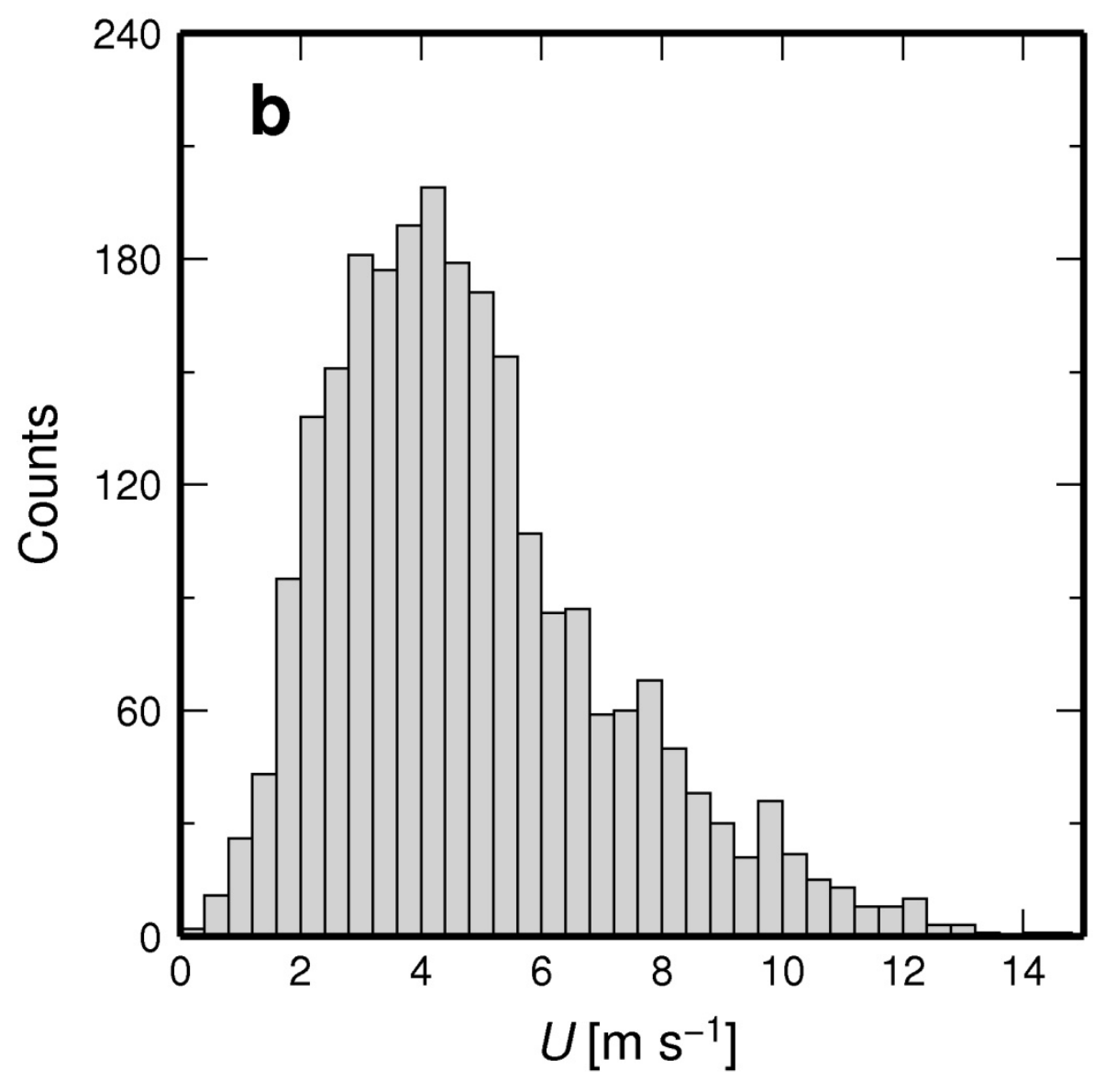

Figure 4b 


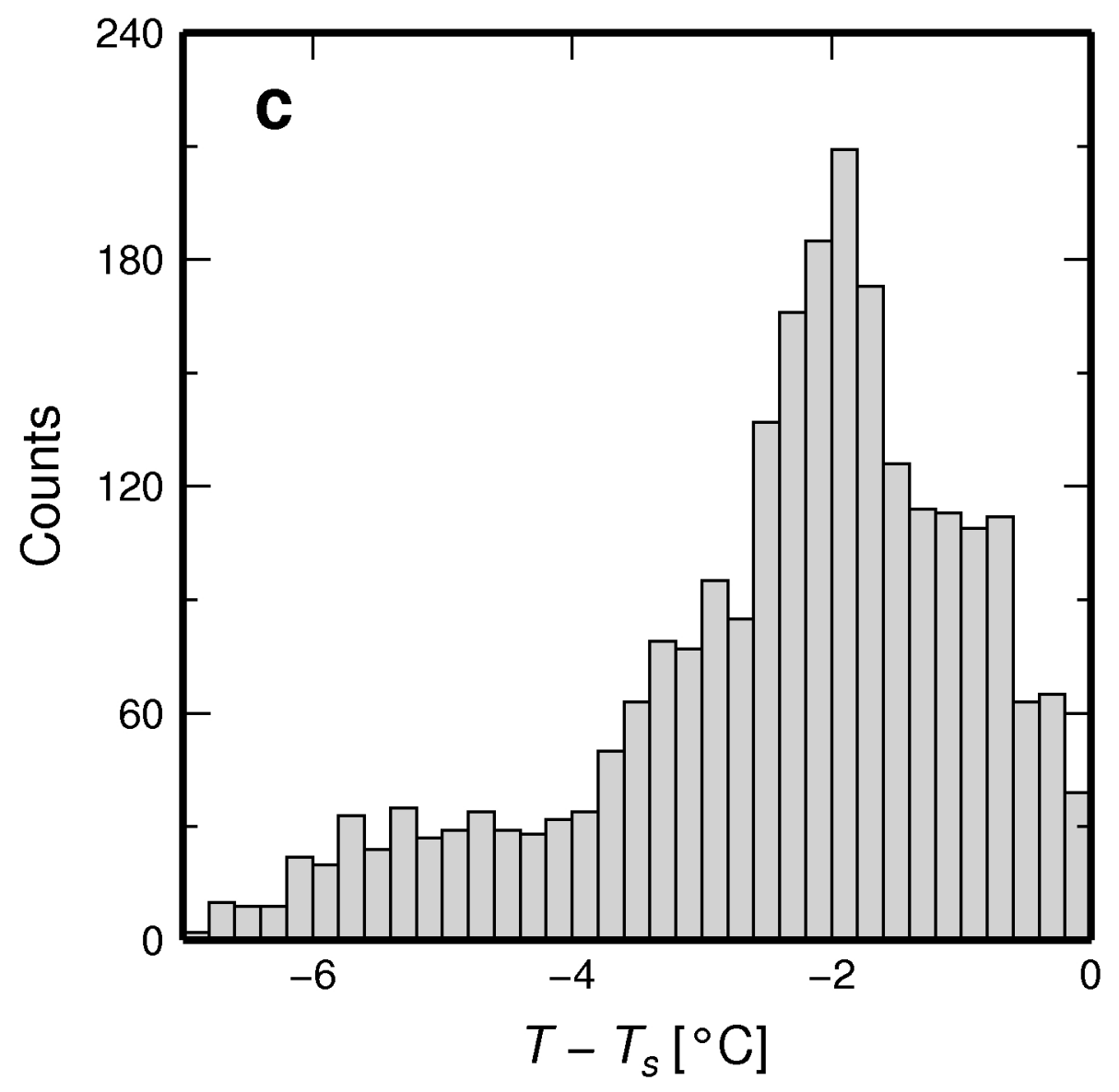

Figure 4c 


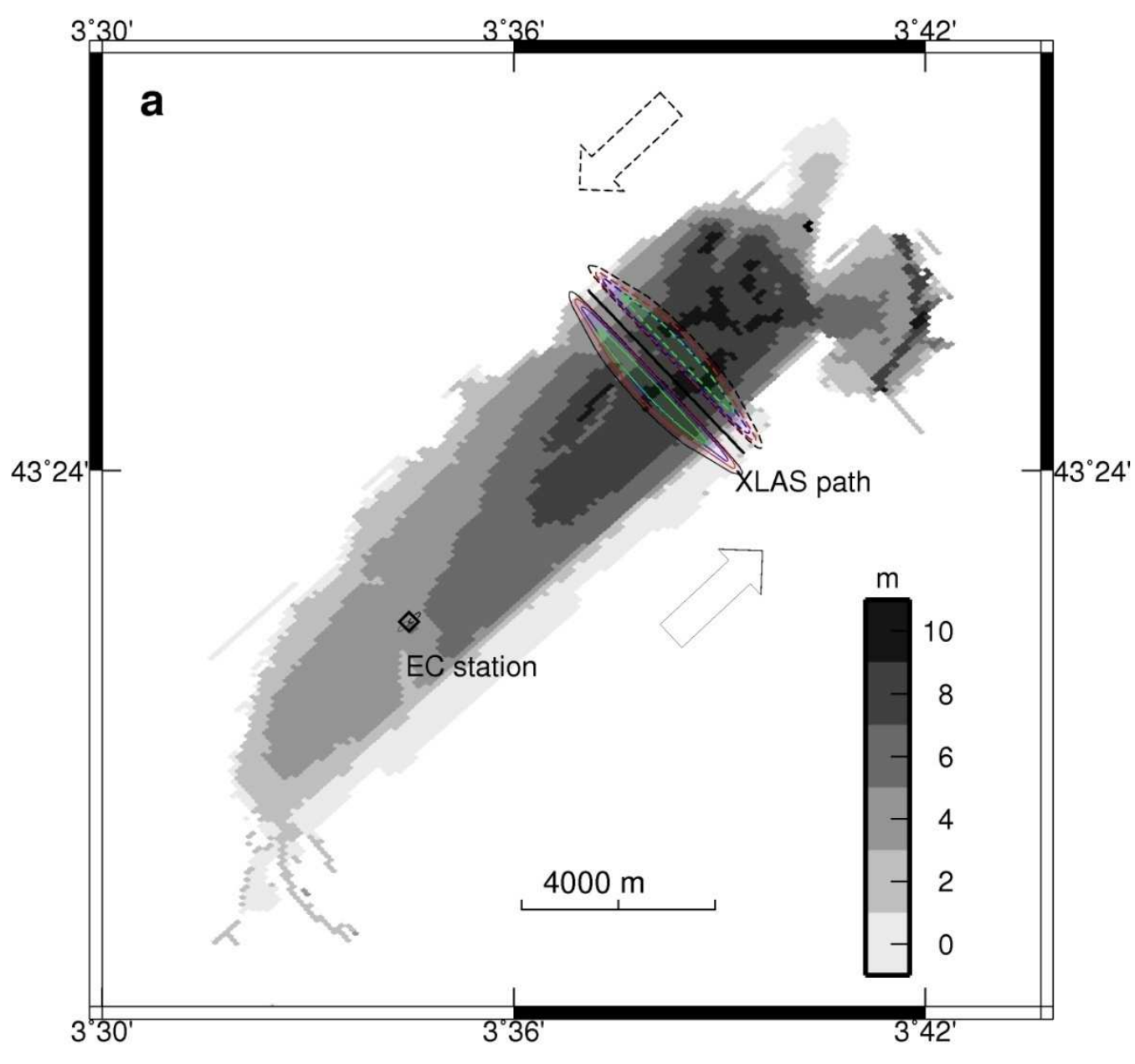

Figure 5a 


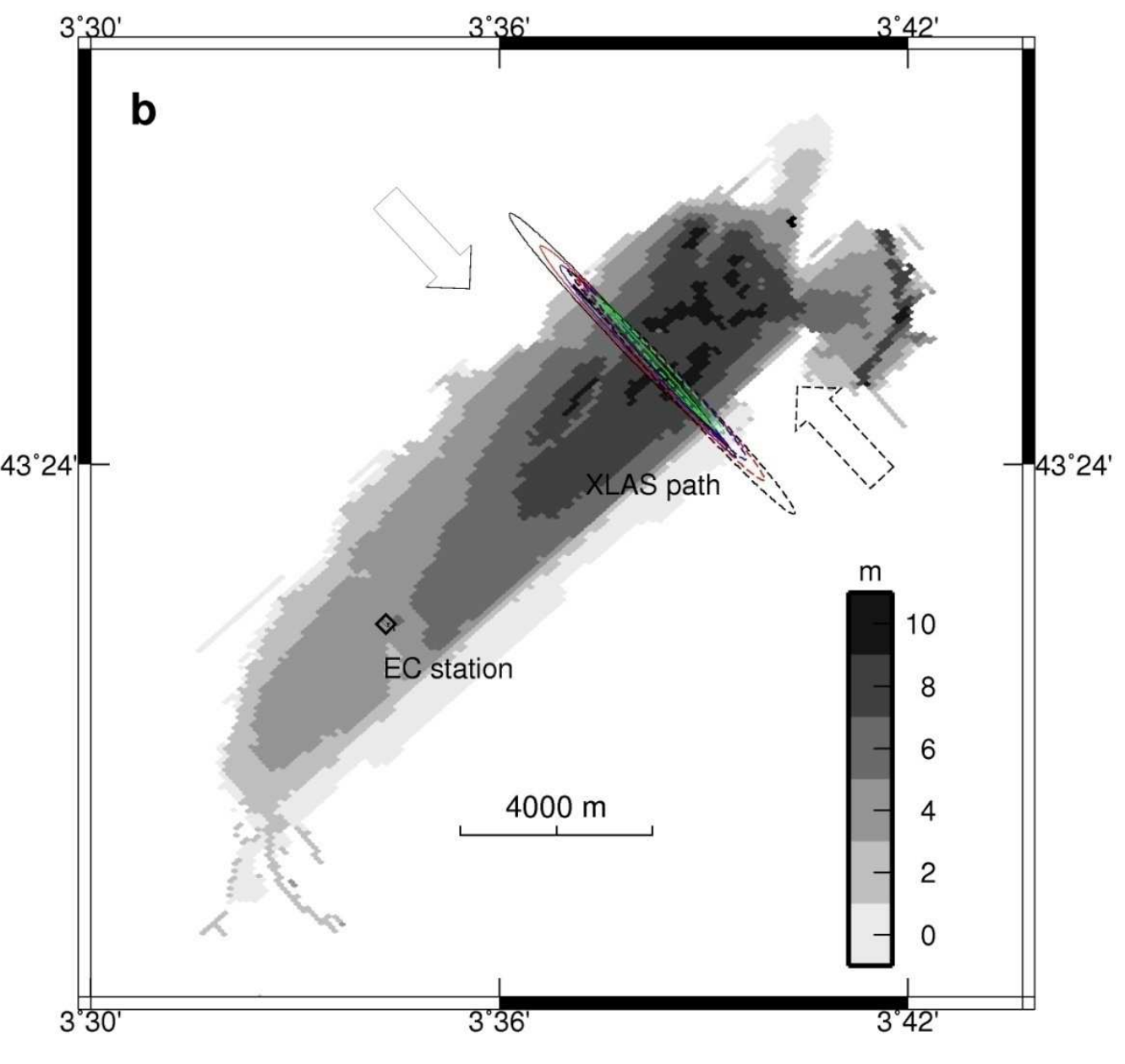

2

Figure 5b 


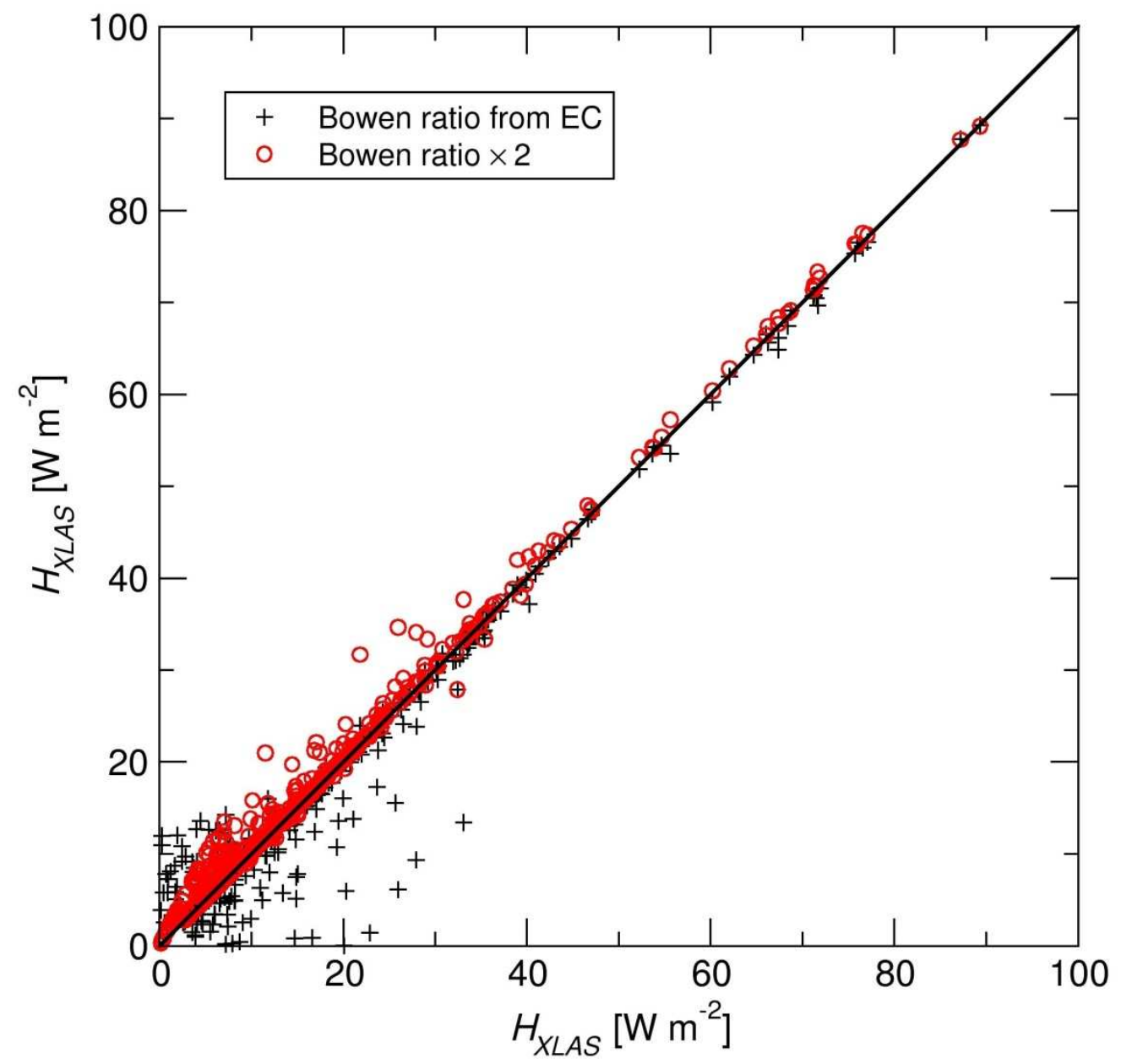

2

Figure 6 


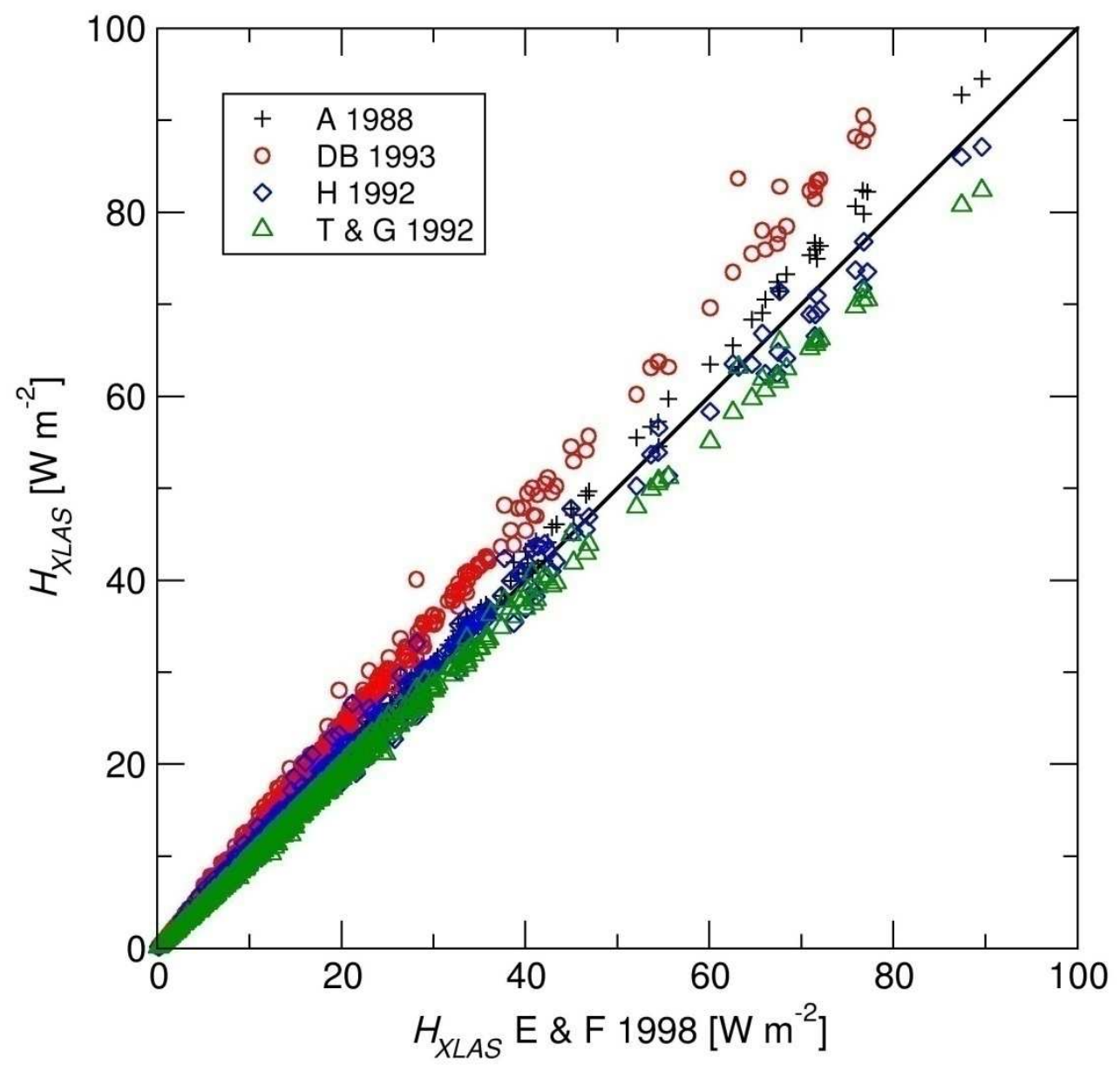

Figure 7

3 


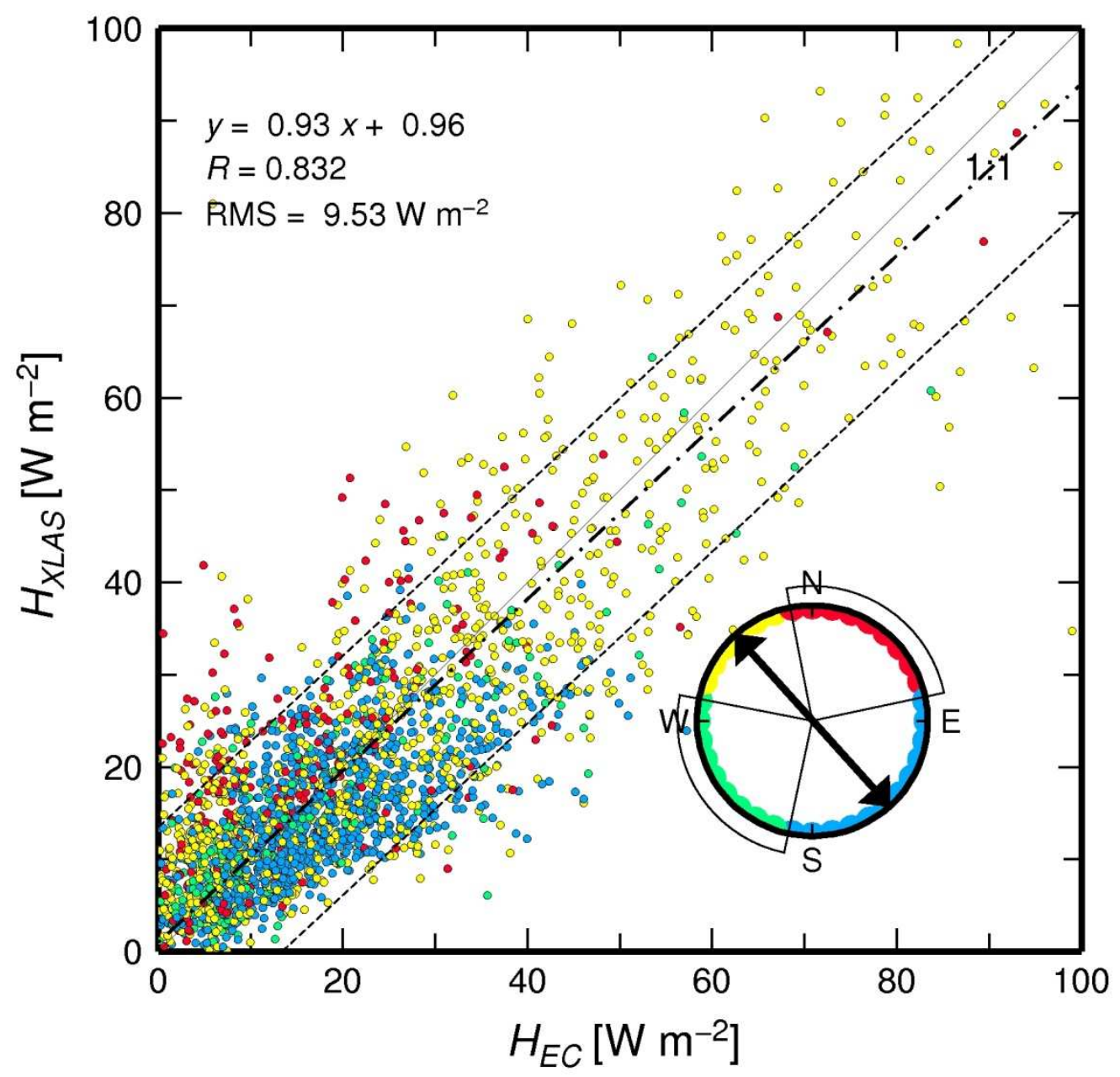

Figure 8 

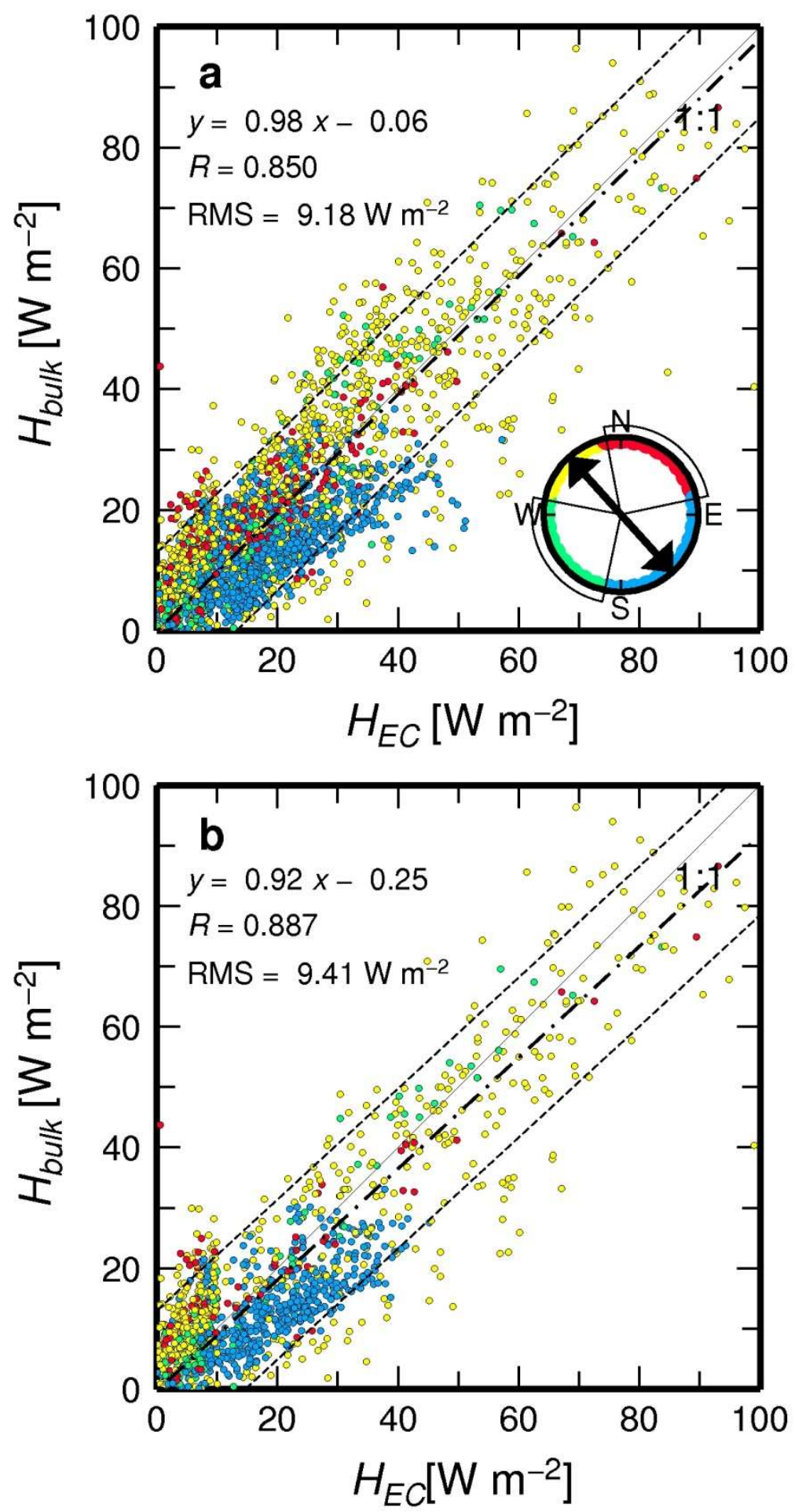

Figure 9 


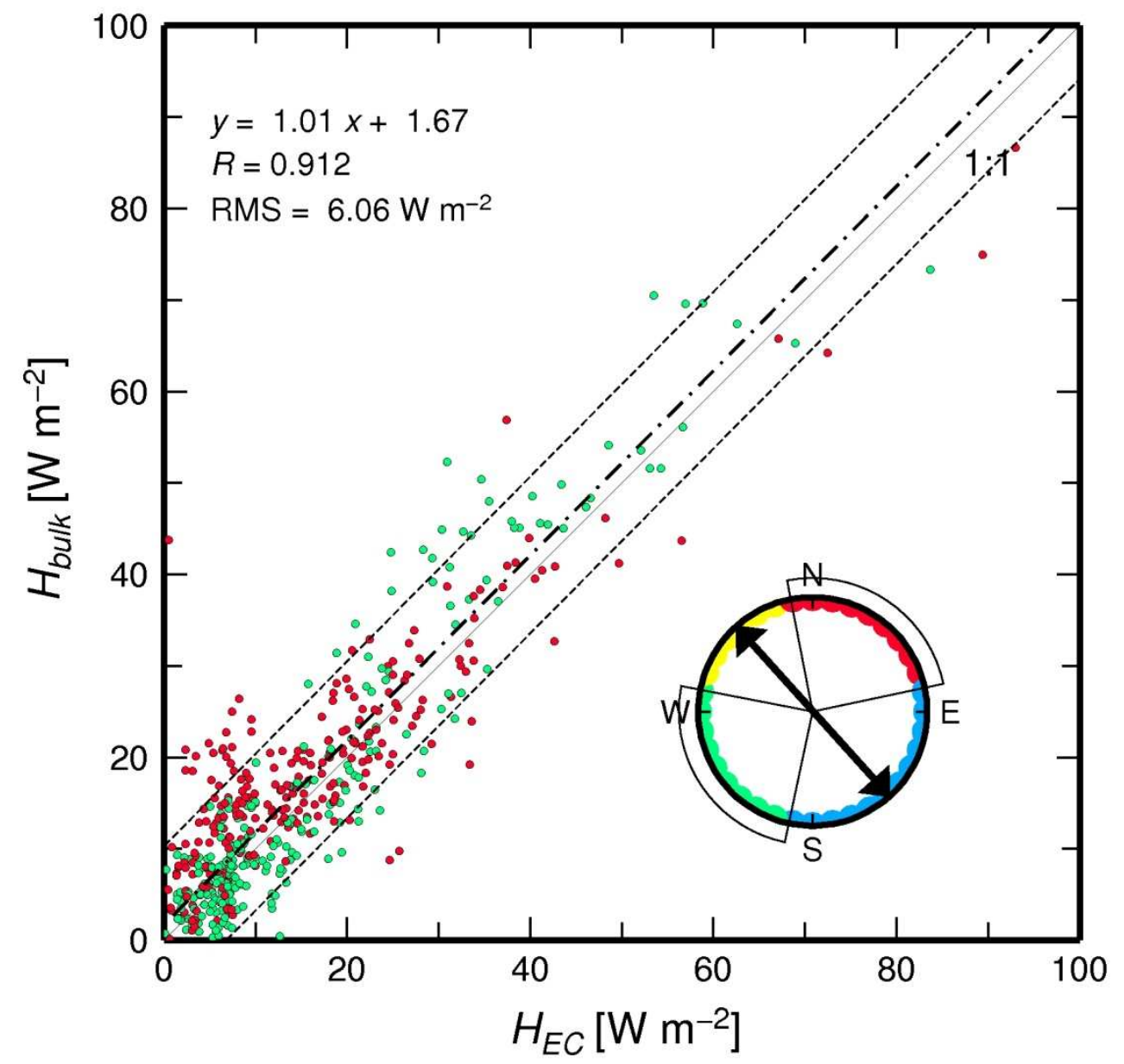

4

Figure 10 


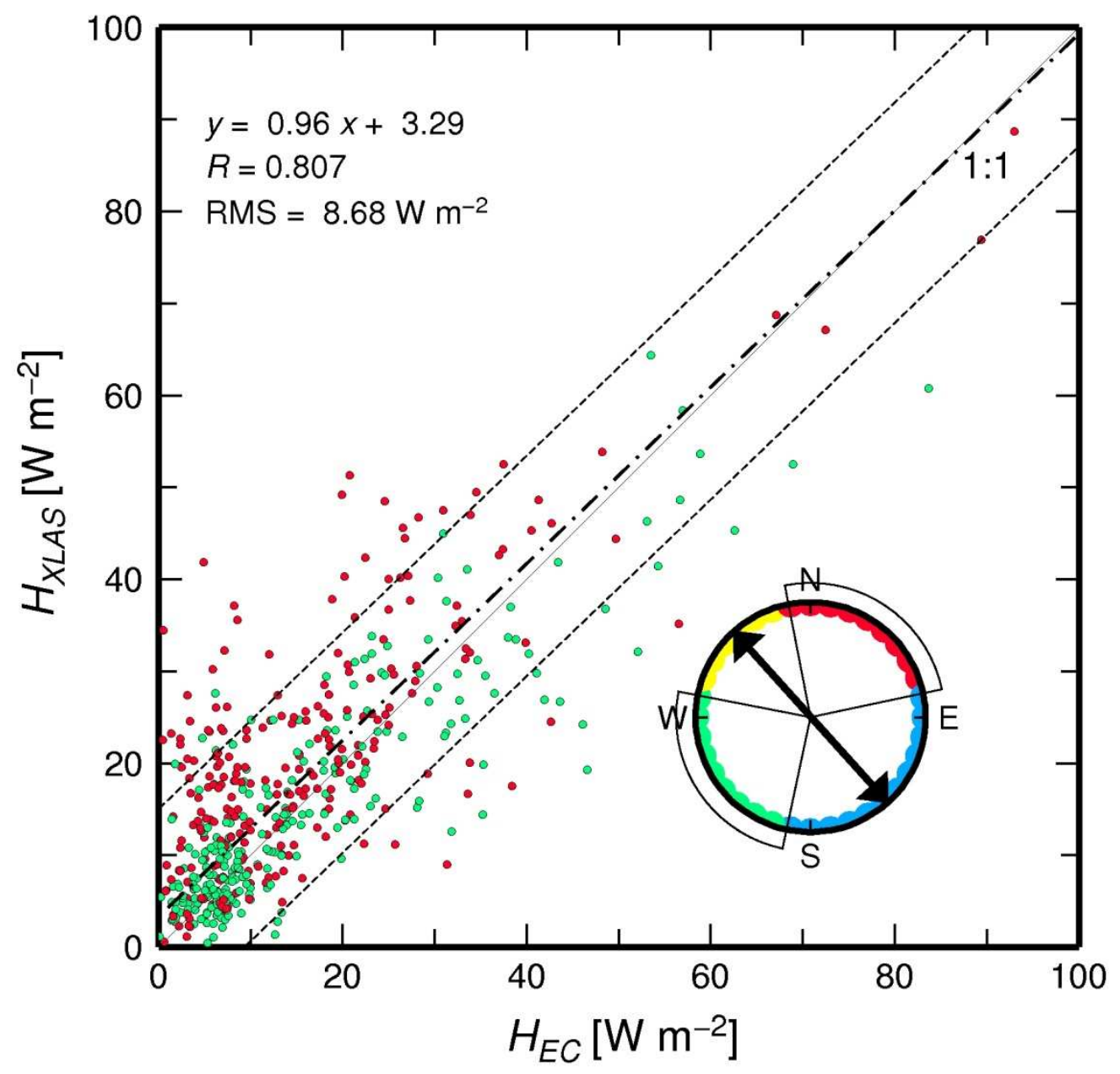

Figure 11 


\begin{tabular}{|c|c|c|c|c|c|}
\hline & $\begin{array}{l}\text { Manufacturer } \\
\text { Type }\end{array}$ & $\begin{array}{l}\text { Sampling } \\
\text { frequency }(\mathrm{Hz})\end{array}$ & $\begin{array}{l}\text { Height/depth/ } \\
\text { orientation } \\
\left(\mathrm{m},{ }^{\circ}\right)\end{array}$ & Site & Precision \\
\hline $\begin{array}{l}\text { 3D sonic } \\
\text { anemometer/thermometer }\end{array}$ & $\begin{array}{l}\text { Gill }^{\mathrm{a}} \\
\text { Horizontal } \\
\text { HS50 }\end{array}$ & 25 & $\begin{array}{l}6 \mathrm{~m} \\
240^{\circ}\end{array}$ & $\bar{M}$ & $\begin{array}{l}\text { Wind < } 1 \% \\
\text { RMS } \\
\text { sound speed } \\
<0.5 \%\end{array}$ \\
\hline $\begin{array}{l}\text { Infra-red hygrometer and } \\
\mathrm{CO}_{2} \text { analyzer }\end{array}$ & LiCor $^{b}$ & 20 & $\begin{array}{l}6 \\
330^{\circ}\end{array}$ & $\bar{M}$ & $\mathrm{H}_{2} \mathrm{O} 3 \%$ \\
\hline Wind speed and direction & Young $^{c}$ & 2 & 6 & $\mathrm{M}, \mathrm{C}, \mathrm{S}$ & $\begin{array}{l}0.3 \mathrm{~m} \mathrm{~s}^{-1} / \\
3^{\circ}\end{array}$ \\
\hline Barometer & $\begin{array}{l}\text { Vaisala }^{\mathrm{d}} \\
\text { PTB220 class A }\end{array}$ & 0.1 & 4 & $\mathrm{~S}$ & $0.2 \mathrm{hPa}$ \\
\hline Air thermometer & $\begin{array}{l}\text { Atexis }^{\mathrm{e}} \\
1000 \mathrm{Ohm} \\
\text { platinum wire } \\
\text { class A }\end{array}$ & 0.1 & 4 & $\begin{array}{l}\mathrm{M}, \mathrm{C}, \\
\mathrm{S}\end{array}$ & $0.2^{\circ} \mathrm{C}$ \\
\hline Hygrometer & $\begin{array}{l}\text { Vaisala }^{\mathrm{d}} \\
\text { HMP45D }\end{array}$ & 0.1 & 4 & $\begin{array}{l}\mathrm{M}, \mathrm{C}, \\
\mathrm{S}\end{array}$ & $3 \%$ \\
\hline Net radiometer & $\begin{array}{l}\text { Kipp \& } \\
\text { Zonen }^{\mathrm{e}} \\
\text { CNR1 }\end{array}$ & 0.1 & 4 & $\mathrm{M}, \mathrm{C}$ & $\begin{array}{l}10 \% \text { daily } \\
\text { average }\end{array}$ \\
\hline Water thermometer & $\begin{array}{l}\text { Atexis }^{\mathrm{f}} \\
1000 \mathrm{Ohm} \\
\text { platinum wire } \\
\text { class A }\end{array}$ & 0.1 & -0.2 & $\begin{array}{l}\mathrm{M}, \mathrm{C}, \\
\mathrm{S}\end{array}$ & $0.2^{\circ} \mathrm{C}$ \\
\hline
\end{tabular}

1 a Lymington, U.K.; ${ }^{\mathrm{b}}$ Atlanta, Nebraska, U.S.A.; ${ }^{\mathrm{c}}$ Traverse City, Michigan, U.S.A; ${ }^{\mathrm{d}}$ Helsinki,

2 Finland; ${ }^{\mathrm{e}}$ Fontenay Trésigny, France; ${ }^{\mathrm{f}}$ Delft, The Netherlands

4 Table 1: Instruments and parameters recorded during the Thau Lagoon experiment. The

5 sites refer to Figure 2: Marseillan (M), Crique (C) or Sète (S).

6 


\begin{tabular}{cccc}
\hline $\begin{array}{c}\text { Steady state } \\
\text { deviation }(\%)\end{array}$ & $\begin{array}{c}\text { Integral turbulence } \\
\text { characteristics } \\
\text { deviation }(\%)\end{array}$ & Final flag & $\begin{array}{c}\text { Percentage of data } \\
(\%)\end{array}$ \\
\hline $0-15$ & $0-30$ & $\mathbf{1}$ & 51 \\
$16-30$ & $0-30$ & $\mathbf{2}$ & 6.5 \\
$1-30$ & $31-75$ & $\mathbf{3}$ & 42.5 \\
\hline
\end{tabular}

1

2 Table 2: TK2 overall flag system, after Foken et al. (2004), and percentage of data for 3 each flag.

4 


\begin{tabular}{|c|c|c|c|}
\hline \multicolumn{2}{|l|}{ Parameter } & $\begin{array}{c}H \text { mean difference } \\
\left(\mathrm{W} \mathrm{m}^{-2}\right)\end{array}$ & $\begin{array}{l}H \text { mean relative } \\
\text { difference }(\%)\end{array}$ \\
\hline$C_{n}^{2}$ & Eq.3/Eq.1 & $0.81 \pm 1.62$ & $5.0 \pm 10.8$ \\
\hline \multirow[t]{2}{*}{$R_{T q}$} & Full/ref & $0.17 \pm 0.48$ & $1.0 \pm 1.8$ \\
\hline & Ref/classical & $-3.35 \pm 2.54$ & $21.0 \pm 8.8$ \\
\hline Bowen & EC/gradient in Eq. 7 & $-0.15 \pm 3.69$ & $11.0 \pm 22.2$ \\
\hline \multirow[t]{7}{*}{ ratio } & +0.2 in Eq. 7 & $-1.28 \pm 6.47$ & $13.1 \pm 48.3$ \\
\hline & EC/gradient in Eq. 13 & $-0.08 \pm 1.75$ & $4.0 \pm 15.9$ \\
\hline & +0.2 in Eq. 13 & $0.01 \pm 0.36$ & $1.5 \pm 2.2$ \\
\hline & EC/gradient & $-0.38 \pm 3.53$ & $11.2 \pm 22.7$ \\
\hline & +0.2 & $-1.67 \pm 4.41$ & $13.8 \pm 48.7$ \\
\hline & $\times 2$ & $0.93 \pm 1.44$ & $8.0 \pm 16.3$ \\
\hline & $\times 0.5$ & $1.09 \pm 1.52$ & $10.9 \pm 15.1$ \\
\hline \multirow[t]{2}{*}{ Humidity } & $T_{v} / T$ & $0.10 \pm 0.07$ & $0.6 \pm 0.2$ \\
\hline & $T_{v^{*}} / T_{*}$ & $3.13 \pm 2.19$ & $29.0 \pm 31.0$ \\
\hline \multirow[t]{2}{*}{$z_{0}$ a priori } & $10^{-5} \mathrm{~m} / 10^{-4} \mathrm{~m}$ & - & $1.0 \pm 5.9$ \\
\hline & $10^{-3} \mathrm{~m} / 10^{-4} \mathrm{~m}$ & - & $1.0 \pm 5.9$ \\
\hline \multirow[t]{3}{*}{$z_{0}$} & fixed mean value/adjusted & $-0.19 \pm 1.34$ & $3.0 \pm 4.2$ \\
\hline & fixed bulk/adjusted & $0.02 \pm 0.60$ & $1.0 \pm 3.9$ \\
\hline & fixed EC/adjusted & $-0.34 \pm 1.46$ & $2.9 \pm 9.9$ \\
\hline \multirow[t]{4}{*}{$\varphi_{T}^{\mathrm{a}}$} & Andreas $1988 b$ & $0.72 \pm 0.96$ & $4.0 \pm 3.2$ \\
\hline & De Bruin et al. 1993 & $3.17 \pm 2.66$ & $18.3 \pm 5.2$ \\
\hline & Hill et al. 1992 & $0.16 \pm 1.14$ & $4.9 \pm 4.7$ \\
\hline & Thiermann and Grassl 1992 & $-0.91 \pm 1.17$ & $4.8 \pm 3.2$ \\
\hline$\psi_{m}{ }^{\mathrm{b}}$ & Beljaars and Holtslag 1991 & $0.00 \pm 0.37$ & $1.1 \pm 2.0$ \\
\hline
\end{tabular}

2 a with respect to the Edson and Fairall (1998) function; ${ }^{b}$ with respect to the Businger-Dyer

3 (Paulson 1970) expression

4 Table 3: XLAS processing, list of sensitivity tests performed. See explanation in text. Bold figures

5 correspond to the most significant absolute effects, grey boxes correspond to the most significant

6 relative effects (more than $10 \%$ mean relative difference). Mean relative differences correspond to

7 absolute values of difference divided by $H$ absolute value. 